Check for updates

Cite this: Phys. Chem. Chem. Phys., 2018, 20, 2676

Received 13th September 2017 Accepted 18th December 2017

DOI: $10.1039 / c 7 c p 06259 a$

rsc.li/pccp

\section{$\sigma$-Holes and $\sigma$-lumps direct the Lewis basic and acidic interactions of noble metal nanoparticles: introducing regium bonds $\dagger$}

\author{
Joakim Halldin Stenlid, (D ${ }^{a}$ Adam Johannes Johansson $\left({ }^{b}{ }^{b}\right.$ and Tore Brinck (iD) ${ }^{a}$
}

\section{Introduction}

During the last few decades nano-sized transition metal particles and clusters have emerged as versatile groups of materials for a wide range of applications such as heterogeneous catalysis, medical therapy and solar energy harvesting. ${ }^{1-6}$ This is largely a reflection of unique properties of the nanoparticles (NPs) in comparison with the corresponding bulk metal, which can be rationalized by perturbations in the electronic structure of the NPs due to atom under-coordination and quantum size effects. ${ }^{7}$ The objective of the current study is to understand the connection between electronic structures of group 11 NPs and their interactions with Lewis bases and Lewis acids. For this purpose, we have employed common DFT-based concepts from molecular theory, and examined their performance in describing the interactions of various $\mathrm{Cu}, \mathrm{Ag}$ and $\mathrm{Au}$ NPs.

\footnotetext{
${ }^{a}$ Applied Physical Chemistry, School of Chemical Science and Engineering, KTH Royal Institute of Technology, Teknikringen 30, SE-100 44, Stockholm, Sweden.E-mail: tore@kth.se

${ }^{b}$ Swedish Nuclear Fuel and Waste Management Company (SKB), Solna, Sweden $\dagger$ Electronic supplementary information (ESI) available. See DOI: 10.1039/ c7cp06259a
}

We shall first consider the molecular electrostatic potential $[V(\mathbf{r})]$, which has been used extensively in the analysis of chemical reactivity and intermolecular interactions. ${ }^{8}$ The electrostatic potential has mainly been used for main group compounds, but recently the applicability domain has been extended to $\mathrm{Cu}, \mathrm{Au}$ and other transition metal NPs. ${ }^{9-13} V(\mathbf{r})$ is rigorously defined by:

$$
V(\mathbf{r})=\sum_{\mathrm{A}} \frac{Z_{\mathrm{A}}}{\left|\mathbf{R}_{\mathrm{A}}-\mathbf{r}\right|}-\int \frac{\rho\left(\mathbf{r}^{\prime}\right) \mathrm{d} \mathbf{r}^{\prime}}{\left|\mathbf{r}^{\prime}-\mathbf{r}\right|}
$$

where $Z_{\mathrm{A}}$ is the charge on nucleus $\mathrm{A}$, located at $\mathbf{R}_{\mathrm{A}}$, and $\rho\left(\mathbf{r}^{\prime}\right)$ is the electron density function. In contrast to other commonly used descriptors, such as partial atomic charges, $V(\mathbf{r})$ is a physical observable that can be determined computationally as well as experimentally. ${ }^{14}$ When analyzing the propensity for intermolecular interactions, it is common to compute and depict $V(\mathbf{r})$ on an isodensity surface defined by the 0.001 a.u. contour of the electron density, ${ }^{8}$ denoted $V_{\mathrm{S}}(\mathbf{r})$.

We have recently demonstrated that the size and shape dependent catalytic properties of gold nanoparticles can be explained using the surface electrostatic potentials of the nanoparticles. ${ }^{13}$ The variations in $V_{\mathrm{S}}(\mathbf{r})$ over the nanoparticles 

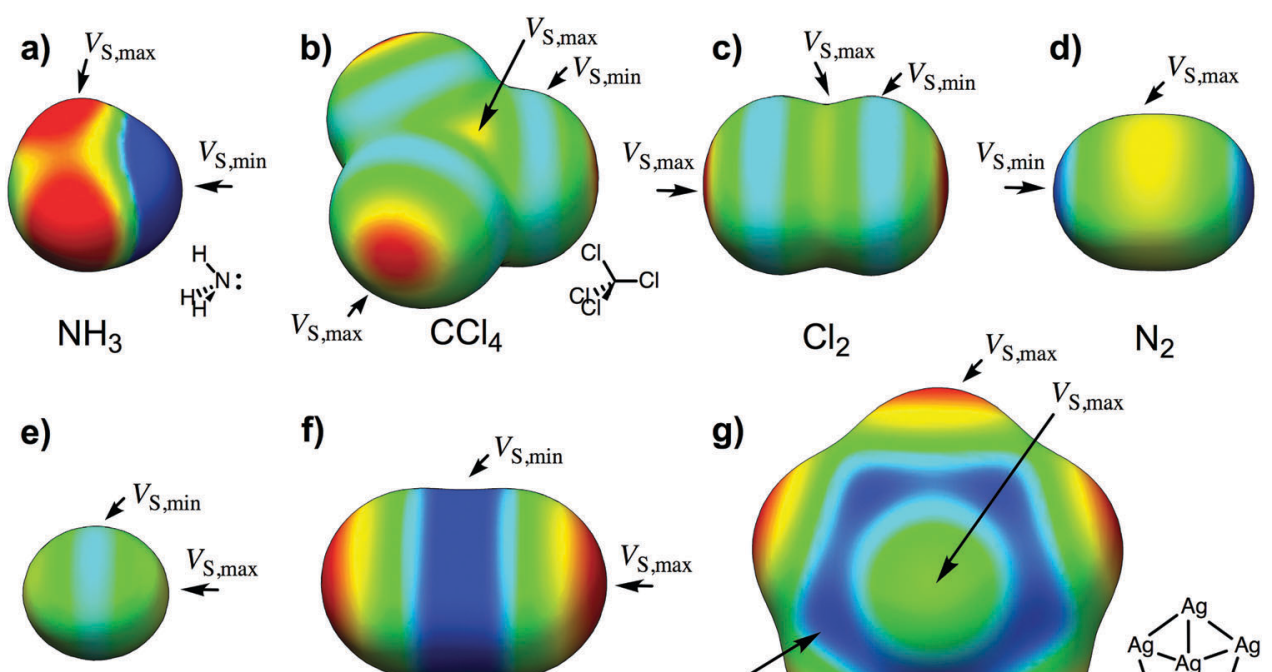

f)
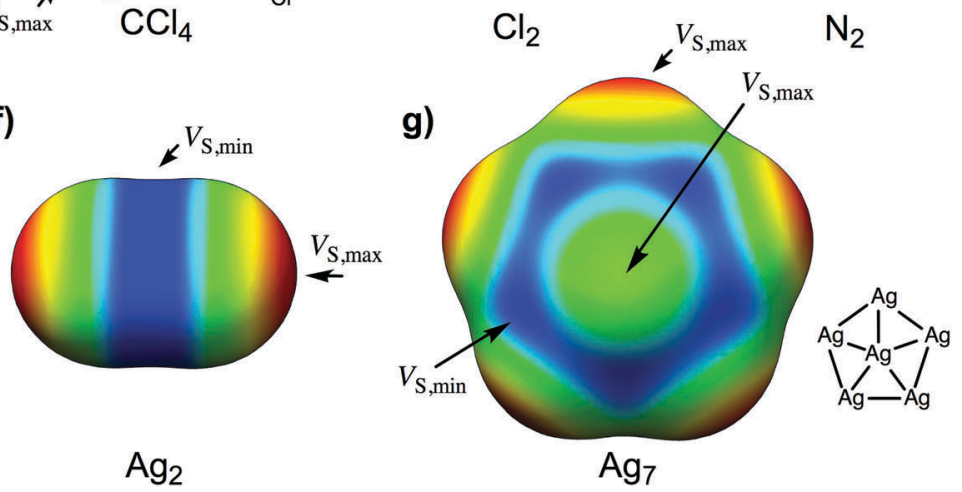

Fig. 1 The electrostatic surface potential $\left[V_{s}(\mathbf{r})\right]$ computed at the 0.001 a.u. isodensity surface for the (a) $\mathrm{NH}_{3}$, (b) $\mathrm{CCl}_{4}$, (c) $\mathrm{Cl}_{2}$, (d) $\mathrm{N}_{2}$, (e) $\mathrm{H}_{2}$, (f) $\mathrm{Ag}_{2}$, and (g) $\mathrm{Ag}_{7}$ compounds. Coloring from high to low potential, central values of the colors in eV in parentheses: red $(0.8)>$ yellow $(0.4)>$ green $(0.0)>$ cyan $(-0.2)>$ blue (0.4). Selected maxima and minima in the surface potential are marked as $V_{S \text {, max }}\left(\sigma\right.$-hole) and $V_{S \text {,min }}(\sigma$-lump) respectively.

were shown to be a consequence of the gold's electron configuration. Here we will use a similar reasoning to explain the interactions of nanoparticles of $\mathrm{Cu}, \mathrm{Ag}$, $\mathrm{Au}$ with Lewis acids and with Lewis bases. ${ }^{13}$ As a background to the analysis, we will elaborate on the derivation from ref. 13, which starts from an atomic perspective. The electrostatic potential of an atom is spherically symmetric, everywhere positive, and decreases asymptotically toward zero at increasing distances from the nucleus. When atoms are combined to form molecules or particles, the electron density is redistributed toward the more electronegative atoms and regions of negative potential are formed. As an example, $V_{\mathrm{S}}(\mathbf{r})$ of ammonia is negative over the electronegative nitrogen, and the minimum, the $V_{\mathrm{S}, \min }$, is located at the lone pair region (Fig. 1a). The magnitude of $V_{\mathrm{S} \text {, min }}$ gives a direct indication of the strength of interactions with Lewis acids or hydrogen bond donors. For the same reason, the hydrogen atoms of ammonia are positive in $V_{\mathrm{S}}(\mathbf{r})$, and the maximum in the surface potential $\left(V_{\mathrm{S}, \max }\right)$ provides a measure of the hydrogen bond donating strength.

An unexpected feature of $V_{\mathrm{S}}(\mathbf{r})$ was first demonstrated by Brinck et al. when analyzing halogenated methanes. ${ }^{15}$ They found that the charge distribution within a chlorine or heavier halogen can be polarized to such an extent that the potential at the end of the halogen is positive even when the halogen is bonded to a less electronegative atom. (For future reference, we define the end as the outermost region of the halogen atom, $\mathrm{X}$, close to the point that intersects the $\mathrm{C}-\mathrm{X}$ axis.) Fig. $1 \mathrm{~b}$ shows this phenomenon on the molecular surface of $\mathrm{CCl}_{4}$, which was one of the molecules of the original study. It was further shown that the positive $V_{\mathrm{S}}(\mathbf{r})$ can explain the tendency of halogen compounds to interact with Lewis bases (nucleophiles); this type of interaction is today referred to as halogen bonding. ${ }^{16}$
Clark et al. later explained the occurrence of the positive potential by a density depletion at the end of the halogen due to polarization of the $\sigma$-orbitals; this was denoted a $\sigma$-hole. ${ }^{17} \mathrm{~A}$ similar type of polarization also exists within the homonuclear diatomics. Fig. 1c shows $V_{\mathrm{S}}(\mathbf{r})$ of $\mathrm{Cl}_{2}$, with the characteristic $\sigma$-hole(s) (i.e. positive $V_{\mathrm{s} \text {, max }}$ ) at the $\mathrm{Cl}$ end(s), and a negative potential region around the middle of each $\mathrm{Cl}$ atom. The latter can be traced to the combined contributions from the $\pi$ and $\pi^{*}$-orbitals and the polarized $\sigma$-orbitals. The L-shaped form of the $\mathrm{Cl}_{2}-\mathrm{Cl}_{2}$ dimer as well as the crystal structure of $\mathrm{Cl}_{2}$ are perfectly consistent with the surface potential of $\mathrm{Cl}_{2}$; the structures are such that $V_{\mathrm{S} \text {,min }}$ of one molecule aligns with $V_{\mathrm{S} \text {,max }}$ of another. ${ }^{18-20}$ Turning toward the $\mathrm{N}_{2}$ molecule, the picture is largely reversed with the most negative potential at the nitrogen tip and the most positive potential at the middle of the bond (Fig. 1d). The latter observation is remarkable considering that the $\pi^{*}$-orbitals are unoccupied and the $\pi$-orbitals are polarized towards the bonding region. This shows that the surface electrostatic potential is largely governed by the highest $\sigma$-orbital. In $\mathrm{N}_{2}$ this orbital is polarized towards the end regions, whereas in $\mathrm{Cl}_{2}$ the orbital is polarized toward the bonding region. Ultimately, this is a reflection of different sp-orbital mixing in the $\sigma$-orbitals of the two compounds: in $\mathrm{Cl}_{2}$ the $3 \mathrm{~s}$ orbitals mix constructively with the phase of the bonding region of the $3 \mathrm{p}_{z}-3 \mathrm{p}_{z} \sigma$-orbital, whereas in $\mathrm{N}_{2}$ the $2 \mathrm{~s}$ orbitals mix deconstructively with the bonding region and constructively with the $2 \mathrm{p}_{z}$ lobes at the $\mathrm{N}_{2}$ ends. Figures of the orbitals are provided in the ESI. $\dagger$ Considering the opposite $\sigma$-orbital polarization of $\mathrm{N}_{2}$ versus $\mathrm{Cl}_{2}$, we find it appropriate to introduce the concept of the $\sigma$-lump to rationalize the negative end, the lone pair, of each $\mathrm{N}$ in $\mathrm{N}_{2}$. The negative lone pair region of $\mathrm{NH}_{3}$ can also, for obvious reasons, be described as a $\sigma$-lump, albeit a much stronger 
$\sigma$-lump than that in $\mathrm{N}_{2}$. In other cases, the $\sigma$-lump is not equivalent to a lone pair and the introduction of this new concept is therefore warranted.

The influence of orbital polarization on the surface electrostatic potential is much easier to interpret when only the valence s-orbitals contribute to bonding, such as in the $\mathrm{H}_{2}$ molecule; the bonding $\sigma$-orbital is polarized toward the bond, resulting in positive ends and a negative potential in the middle of the bond (Fig. 1e). In other words, there are $\sigma$-holes at each end region and a $\sigma$-lump in the middle. $V_{\mathrm{S}}(\mathbf{r})$ of $\mathrm{Li}_{2}$ (not shown) has a similar pattern, but the $\sigma$-holes are stronger and the lump is much more diffuse due to the larger polarizability and the much longer bond length of $\mathrm{Li}_{2}$. The noble metals, $\mathrm{Cu}, \mathrm{Ag}$ and $\mathrm{Au}$, resemble $\mathrm{H}$ and $\mathrm{Li}$ in that it is mainly the half-filled s valence orbitals that contribute to chemical bonding. Consequently, the surface electrostatic potential of $\mathrm{Ag}_{2}$ is similar to that of $\mathrm{H}_{2}$, but the magnitudes of the $V_{\mathrm{S} \text {, max }}$ and $V_{\mathrm{S} \text {, min }}$ are larger (Fig. 1f). The relevance of the surface potential for the intermolecular interaction tendencies is demonstrated by the $\mathrm{Ag}_{2}$ 's preference to form T-shaped dimers and to interact end-on with Lewis bases and side-on (middle of the bond) with Lewis acids (see Section S1 of the ESI $\dagger$ ).

We can now ask the question whether the $\sigma$-orbital polarization, and the positive and negative potential regions resulting from the $\sigma$-holes and $\sigma$-lumps, respectively, also govern the interactions of larger metal NPs with Lewis bases and Lewis acids. It is anticipated that metal atoms that are not fully coordinated have associated $\sigma$-holes that are potential sites for interactions with Lewis bases, and that the magnitude of $V_{\mathrm{S} \text {,max }}$ at these sites reflects the relative interaction energies at each site. Similarly, we expect that exposed bonds, i.e. $\sigma$-lumps, are likely to interact with Lewis acids and that the interaction strengths can be predicted from $V_{\mathrm{S} \text {,min }}$ (other factors such as chargetransfer and polarization affecting a compound's interaction behavior are discussed below). The surface electrostatic potential of $\mathrm{Ag}_{7}$ is in agreement with the painted picture (Fig. 1g), i.e. the regions of the most positive potential are found at the exposed atoms and are opposite to the chemical bonds, and the negative potential regions are found at the exposed bonds, as well as in the hollow sites in-between atoms. In the following, we will demonstrate that the positions and magnitudes of $V_{\mathrm{S} \text {,min }}$ and $V_{\mathrm{S} \text {,max }}$ can be used to identify and rank sites that interact with Lewis acids and Lewis bases, respectively.

It must be emphasized that intermolecular interactions are not solely electrostatic in nature but also have attractive contributions from charge-transfer, polarization and dispersion, as well as repulsive contributions from the Pauli repulsion. Although such a division is artificial, and particularly the differentiation between polarization and charge-transfer is arbitrary, the consideration of different interaction terms can aid the interpretation and prediction of intermolecular interactions. The multifaceted nature of Lewis acid-base interactions was acknowledged already by Pearson who classified Lewis acids and bases as hard or soft. ${ }^{21}$ Interactions between hard acids and hard bases are considered electrostatically controlled, whereas soft-soft interactions have significant contributions from

$$
\begin{aligned}
& \mathrm{H}_{3} \mathrm{~N}: \cdots \mathrm{H}-\mathrm{OR}_{2} \\
& \text { Hydrogen bond } \\
& \mathrm{H}_{3} \mathrm{~N}: \cdots \mathrm{X}-\mathrm{R}_{2} \quad \mathrm{X}=\mathrm{Cl}, \mathrm{Br}, \mathrm{I} \\
& \text { Halogen bond } \\
& \mathrm{H}_{3} \mathrm{~N}: \cdots \mathrm{M}^{0}-\mathrm{R}_{2} \quad \mathrm{M}=\mathrm{Au}, \mathrm{Ag}, \mathrm{Cu} \\
& \text { Regium bond }
\end{aligned}
$$

Scheme 1 Comparison between hydrogen, halogen and regium bonds.

charge-transfer/polarization. While $V(\mathbf{r})$ for obvious reasons is well suited for the characterization of the electrostatic contribution, it does not capture e.g. charge-transfer/polarization effects. Sjoberg et al. ${ }^{22}$ recognized this when they introduced the average local ionization energy $[\bar{I}(\mathbf{r})]$. This property gives a measure of the local cost of ionizing a compound, and, in addition to electrostatics, also reflects the local charge-transfer/polarization capacity of a compound. Surface minima in $\bar{I}(\mathbf{r})$ correspond to sites susceptible to interactions with electron-accepting species (Lewis acids), but cannot be used to characterize interactions with electron donors (Lewis bases). Brinck et al. ${ }^{23}$ recently introduced the local electron attachment energy, $E(\mathbf{r})$, as a complement to $\bar{I}(\mathbf{r})$. Contrary to $\bar{I}(\mathbf{r})$, surface minima in $E(\mathbf{r})$ correspond to sites where the compound is likely to accept an electron. Hence these sites will, similar to $V_{\mathrm{S}, \max }$, correspond to areas susceptible to interactions with Lewis bases. The $\bar{I}(\mathbf{r})$ and $E(\mathbf{r})$ properties have been proven to be useful tools in the study of molecular interactions including non-covalent bonding as well as local reactivity. ${ }^{23-26}$ The performance of $\bar{I}(\mathbf{r})$ and $E(\mathbf{r})$ in the studied NP interactions will here be compared to $V(\mathbf{r})$ in order to better characterize the origin of the interactions.

Owing to the close resemblance between halogen/hydrogen bonding and the interactions of noble metal NP with Lewis basis, we shall also introduce a new class of bonds - regium bonds, reflecting the royal position of $\mathrm{Cu}, \mathrm{Ag}$ and $\mathrm{Au}$ among the elements in the periodic table. In analogy to halogen or hydrogen bonds, regium bonds are controlled by the polarization of $\sigma$-orbitals, and takes place between a charge acceptor (in this case a noble metal atom) displaying a high electrostatic potential, i.e. a $\sigma$-hole, and a electron donor with a negative electrostatic potential (for instance the $\mathrm{N}$ atom of $\mathrm{NH}_{3}$ ). Scheme 1 gives a comparison between hydrogen, halogen and regium bonding.

\section{Methods}

\subsection{Theory}

In this section, the theoretical foundation of the $\bar{I}(\mathbf{r})$ and $E(\mathbf{r})$ properties is provided. An account of their practical evaluation and physiochemical significance is also included. Firstly, the use of isodensity surfaces, such as the 0.001 a.u. isosurface, for the evaluation of the descriptor properties used herein deserves an explanation. Chemical interactions and reactions take place at a certain distance from the nuclear framework that constitutes the molecule or particle. In line with this, it has been 
found that the evaluation of $V_{\mathrm{S}}(\mathbf{r})$ and $\bar{I}_{\mathrm{S}}(\mathbf{r})$ at a distance from the nuclei corresponding to a constant electron density of 0.001 a.u. [0.004 a.u. for $E_{\mathrm{S}}(\mathbf{r})$ ], typically marginally more diffuse [dense] than the van der Waals surface, is often a good choice for both qualitative and quantitative studies..$^{8,23,25}$ In addition by performing the evaluation at a constant density, the analysis is simplified since the Pauli repulsion resulting from the intermolecular electron density overlap will be approximately constant when comparing different adsorption sites of the compound.

The average local ionization energy. The average local ionization energy $\bar{I}(\mathbf{r})$ is rigorously defined within the Hartree-Fock (HF) approximation as well as in Kohn-Sham DFT (KS-DFT), and provides the local energy cost for removal of an electron from the studied system. $\bar{I}(\mathbf{r})$ is described by: ${ }^{22,25}$

$$
\bar{I}(\mathbf{r})=\sum_{\mathrm{i}}^{\mathrm{HOMO}} \frac{-\varepsilon_{\mathrm{i}} \rho_{\mathrm{i}}(\mathbf{r})}{\rho(\mathbf{r})}
$$

where, $\varepsilon_{\mathrm{i}}$ is the eigenvalue of the ith spin orbital. The summation runs over all occupied orbitals up to the highest occupied (molecular) orbital, HOMO. Local minima in $\bar{I}(\mathbf{r})$ on an isodensity surface (typically 0.001 a.u.), $\bar{I}_{\mathrm{S}, \mathrm{min}}$, correspond to Lewis basic sites. $\bar{I}_{\mathrm{S}}(\mathbf{r})$ is thus a descriptor of the local electron donation power (i.e. Lewis basicity) of the studied compound; while $V_{\mathrm{S}}(\mathbf{r})$ provides information on both Lewis basicity and acidity. In contrast to $V(\mathbf{r})$, which only contains information about the electrostatic interaction tendencies, $\bar{I}(\mathbf{r})$ also provides information on the charge-transfer/polarization capabilities of a compound. This can be demonstrated by decomposing the $\bar{I}(\mathbf{r})$ property into contributions of the electrostatic potential, the local electron temperature, $T(\mathbf{r})$, and the local exchange-correlation potential, $V_{\mathrm{xc}}(\mathbf{r})$, as: ${ }^{27}$

$$
\bar{I}(\mathbf{r})=-\frac{3}{2} k T(\mathbf{r})+V(\mathbf{r})-V_{\mathrm{xc}}(\mathbf{r})
$$

The local electron temperature $T(\mathbf{r})$ is related to the local kinetic energy density, $t_{\mathrm{s}}(\mathbf{r})$, by $3 k T(\mathbf{r}) / 2=t_{\mathrm{s}}(\mathbf{r}) / \rho(\mathbf{r})$. Besides the electrostatic potential, $V(\mathbf{r})$, it is mainly $t_{\mathrm{s}}(\mathbf{r})$ that determines the variation of $\bar{I}(\mathbf{r})$ over an isodensity surface, since $V_{\text {xc }}(\mathbf{r})$ is nearly constant at constant density. Surface minima in $\bar{I}(\mathbf{r})\left[\bar{I}_{\mathrm{S}, \mathrm{min}}\right]$ are typically found in lone pair regions and over $\pi$-bonds, and their magnitudes reflect the strength of interactions with Lewis acids. When going down the periodic table for congeners of Lewis bases, $\bar{I}_{\mathrm{S} \text {,min }}$ decreases and $V_{\mathrm{S}, \text { min }}$ increases indicating that $t_{\mathrm{S}}(\mathbf{r})$ is largely responsible for the soft (charge transfer/polarization) character of $I(\mathbf{r})$ compared to $V(\mathbf{r})$, e.g. comparing $\mathrm{H}_{2} \mathrm{O}$ and $\mathrm{H}_{2} \mathrm{~S}$, the latter has a much lower $\bar{I}_{\mathrm{S} \text {, min }}$ despite its higher $V_{\mathrm{S}, \mathrm{min}} \cdot{ }^{28}$ Hence, $\bar{I}(\mathbf{r})$ and $V(\mathbf{r})$ provide complementary information. This feature will herein be exploited in the evaluation of the electrostatic versus charge-transfer/polarization character of nanoparticle interactions.

The local electron attachment energy. The local electron attachment energy, $E(\mathbf{r})$, was introduced by Brinck et $a l^{23}$ as a corresponding property to $\bar{I}(\mathbf{r})$ for the analysis of local Lewis acidity. $E(\mathbf{r})$ can be seen as a modified version of the electron affinity descriptor $\mathrm{EA}_{\mathrm{L}}(\mathbf{r})$ of Clark and co-workers ${ }^{29,30}$ and sums the contribution of all virtual (unoccupied) orbitals with a negative eigenvalue. $E(\mathbf{r})$ is evaluated by:

$$
E(\mathbf{r})=\sum_{\mathrm{i}=\mathrm{LUMO}}^{\varepsilon_{\mathrm{i}}<0} \frac{\varepsilon_{\mathrm{i}} \rho_{\mathrm{i}}(\mathbf{r})}{\rho(\mathbf{r})}
$$

$E(\mathbf{r})$ differs from $\mathrm{EA}_{\mathrm{L}}(\mathbf{r})$ in the use of a cut-off $\varepsilon_{\mathrm{i}}<0$ in the selection of virtual orbitals and in the definition of the denominator, where $\mathrm{EA}_{\mathrm{L}}(\mathbf{r})$ employs the total virtual orbital density whereas $E(\mathbf{r})$ uses the occupied orbital density. $\neq$ The cut-off is motivated since, within the generalized Kohn-Sham method (GKS-DFT) and given a frozen orbital approximation, only the orbitals with negative eigenvalues will bind a fractional electron, as follows directly from Janak's theorem. ${ }^{23,31}$ Analogous to $\bar{I}(\mathbf{r})$, $E(\mathbf{r})$ includes contributions from both the electrostatic potential and $V_{\mathrm{xc}}$, as well as the kinetic energy densities of the virtual orbitals. $E(\mathbf{r})$ can be decomposed as: ${ }^{23}$

$$
E(\mathbf{r})=\frac{1}{\rho(\mathbf{r})}\left[\sum_{\mathrm{i}=\mathrm{LUMO}}^{\varepsilon_{\mathrm{i}}<0} t_{\mathrm{i}}(\mathbf{r})-V(\mathbf{r}) \sum_{\mathrm{i}=\mathrm{LUMO}}^{\varepsilon_{\mathrm{i}}<0} \rho_{\mathrm{i}}(\mathbf{r})+V_{\mathrm{xc}}(\mathbf{r}) \sum_{\mathrm{i}=\mathrm{LUMO}}^{\varepsilon_{\mathrm{i}}<0} \rho_{\mathrm{i}}(\mathbf{r})\right]
$$

In eqn (5) $t_{\mathrm{i}}(\mathbf{r})=-\frac{1}{2} \psi_{\mathrm{i}}^{*}(\mathbf{r}) \nabla^{2} \psi_{\mathrm{i}}(\mathbf{r})$. As in the case of $\bar{I}(\mathbf{r}), E(\mathbf{r})$ can thus be used as a complement to $V(\mathbf{r})$ in the evaluation of the charge-transfer/polarization versus the electrostatic character of a given interaction. $E(\mathbf{r})$ gives the local electron accepting capability (Lewis acidity) of a compound and minima in $E(\mathbf{r})$ on an isodensity surface, $E_{\mathrm{S} \text {,min }}$, correspond to Lewis acidic sites.

In contrast to $V_{\mathrm{S}}(\mathbf{r})$ and $\bar{I}_{\mathrm{S}}(\mathbf{r})$, a small benchmark test on organic molecules, comprising aromatic compounds, unsaturated alkenes and halogen bonding molecules, has previously shown that it is more appropriate to evaluate $E_{\mathrm{S}}(\mathbf{r})$ on the 0.004 a.u. isodensity surface rather than the 0.001 a.u. surface. ${ }^{23} E_{\mathrm{S}}(\mathbf{r})$ is hence obtained at slightly shorter distances from the nucleus than $V_{\mathrm{S}}(\mathbf{r})$ and $\bar{I}_{\mathrm{S}}(\mathbf{r})$. However, the proper isosurface for interaction analysis on metal NPs remains to be established. In the present study we have thus computed $E_{\mathrm{S}}(\mathbf{r})$ on both the 0.001 and 0.004 a.u. isodensity surfaces.

\subsection{Computational details}

The $\mathrm{Cu}_{9}, \mathrm{Au}_{9}, \mathrm{Ag}_{9}, \mathrm{Ag}_{11}, \mathrm{Ag}_{17}$ and $\mathrm{Ag}_{18}$ nanoparticle structures were studied using the Gaussian 09 program suite. ${ }^{32}$ The structures were chosen on the basis that they have multiple unique adsorption sites and are of a size that is of technical interest while being computationally manageable. In our previous study we studied $\mathrm{Au}$ nanoparticles in the size from $\mathrm{Au}_{2}$ to $\mathrm{Au}_{561}$ and found similar variations in $V_{\mathrm{S}}(\mathbf{r})$ independent of the particle size. ${ }^{13}$ All but the $\mathrm{Ag}_{18}$ particles are doublets in their ground states, while $\mathrm{Ag}_{18}$ is a closed-shell singlet. Adsorption energies of the electron donating $\mathrm{H}_{2} \mathrm{O}, \mathrm{NH}_{3}$ and $\mathrm{H}_{2} \mathrm{~S}$ molecules and electron accepting $\mathrm{Na}^{+}, \mathrm{HCl}$ (H-down), $\mathrm{BH}_{3}$ and $\mathrm{BF}_{3}$ species were determined at the PBE0-D3(BJ)/def2-TVZPP//PBE0-D3(BJ)/def2-TVZP

$\$$ Note that in KS-DFT most neutral compounds have one or more virtual orbital(s) with negative eigenvalue(s), exceptions are e.g. small and hard molecules such as $\mathrm{H}_{2} \mathrm{O}$. The NPs considered in this study have 22-40 virtual orbitals of negative eigenvalue (see Table 1). 
level of theory ${ }^{33-36}$ using effective core potentials (ECP) ${ }^{36}$ for the $\mathrm{Ag}$ and $\mathrm{Au}$ particles. $\S$ The CO-adsorption energies were obtained from ref. 37. In previous studies it has been found that the use of hybrid functionals, such as PBE0,$^{33}$ improves the description of transition metal-adsorbate interactions compared to standard GGA functionals. ${ }^{38-43}$ Likewise, one has found that the inclusion of dispersion (via e.g. Grimme's D3 dispersion corrections ${ }^{34}$ with Becke-Johnson (BJ) damping ${ }^{35}$ ) improves the energetics and structures of e.g. Au nanoparticles ${ }^{34}$ and other transition metal adsorbate systems. ${ }^{44,45}$ All structures were characterized as local minima (zero imaginary frequencies) by vibrational analysis employing the harmonic oscillator approximation. Interaction energies, $\Delta E_{\text {int }}$, were determined by:

$$
\Delta E_{\mathrm{int}}=E_{\mathrm{Ads} / \mathrm{NP}}-\left(E_{\mathrm{Ads}}+E_{\mathrm{NP}}\right)
$$

where $E_{\mathrm{Ads} / \mathrm{NP}}, E_{\mathrm{NP}}$ and $E_{\mathrm{Ads}}$ are the zero-point corrected BornOppenheimer electronic energies of the nanoparticle-adsorbate complex, the bare nanoparticle, and the free adsorbate molecule, respectively. $\Phi$ Due to considerable $\mathrm{Au}_{9}$ structural changes upon $\mathrm{H}_{2} \mathrm{~S}$ adsorption onto some of the adsorption sites, interaction energies are reported for an optimized structure with the Au atoms fixed in order to facilitate comparison to the descriptor values. Thermal corrections were obtained at the fully relaxed structures.

The modified $\mathrm{PBE}^{33}$ exchange-correlation functional with Hartree-Fock exchange $\left(E_{\mathrm{x}}^{\mathrm{HF}}\right)$ reduced to $10 \%$ was used in the evaluation of the $V(\mathbf{r}), E(\mathbf{r})$ and $\bar{I}(\mathbf{r})$ properties. The choice of functional was based on an evaluation of a set of functionals ranging from the pure GGA $\mathrm{PBE}^{46}$ to the hybrid PBE0 with different amounts of $E_{\mathrm{x}}^{\mathrm{HF}}$ (up to $66.67 \%$ ), see Section $\mathrm{S} 4$ of the ESI. $\dagger$ Also included in the evaluation were the range separated HSE06, ${ }^{47,48}$ the long-range corrected LC- $\omega \mathrm{PBE}^{49}$ and the $\mathrm{TPSSh}^{50,51}$ meta hybrid functionals, as well as the hybrid $\mathrm{B} \mathrm{LYP}^{52,53}$ functional and its long-range corrected version CAM-B3LYP. ${ }^{54}$ The evaluation underlines that a reduced $E_{\mathrm{x}}^{\mathrm{HF}}$ increases the quality of the $E(\mathbf{r})$ and $\bar{I}(\mathbf{r})$ descriptors, especially at the denser isosurfaces (e.g. 0.004 a.u.). In contrast $V(\mathbf{r})$ is relatively insensitive to the amount of $E_{\mathrm{x}}^{\mathrm{HF}}$. The use of a reduced amount of $E_{\mathrm{x}}^{\mathrm{HF}}$ for DFT calculations of transition-metal compounds is not new, but in-fact a common practice: the so-called B3LYP ${ }^{* 55}$ and PBE0 ${ }^{* 56}$ functionals with $10-15 \% E_{\mathrm{x}}^{\mathrm{HF}}$ have for instance been used to describe spin-transitions ${ }^{55,56}$ and to study enzymatic processes involving redox active open-shell transition metal ions. ${ }^{57,58}$

We have also found that the combination of the LACV3P*// LANL2-DZ basis sets, ${ }^{59-62}$ employing the Los Alamos type ECPs for the transition metal atoms, yields results of similar quality for the descriptors as the considerably larger def2 basis set family of Ahlrichs and co-workers ${ }^{36}$ (i.e. the basis set used for the $\Delta E_{\text {int }}$ determination). Hence, in order to show that the descriptors can

$\S$ Relativistic effects are important, in particular for Au compounds, and affect the geometry and chemical properties significantly. By the use of ECPs scalar relativistic effects are implicitly accounted for. We have previously showed that ECP and relativistic all-electron calculations yield similar results. ${ }^{13}$

T At the considered level of theory basis set superposition errors (BSSEs) are small. Using a similar computational set up for $\mathrm{H}_{2} \mathrm{O}$ adsorption onto the $\mathrm{Cu}_{7}$ nanoparticle we have previously found a BSSE of $0.06 \mathrm{eV} .^{9}$ provide accurate predictions at a low computational cost we have employed the LACV3P*//LANL2-DZ basis set combination for the $V_{\mathrm{S}}(\mathbf{r}), E_{\mathrm{S}}(\mathbf{r})$ and $\bar{I}_{\mathrm{S}}(\mathbf{r})$ descriptors throughout this study. The in-house program HS95 (T. Brinck) was used to compute the descriptor values; if not otherwise stated, $V_{\mathrm{S}}(\mathbf{r}), E_{\mathrm{S}}(\mathbf{r})$ and $\bar{I}_{\mathrm{S}}(\mathbf{r})$ were evaluated on the 0.001 a.u. isodensity surface, since this isosurface was found to generally give the best correlation with computed $\Delta E_{\text {int }}$ (see the results and discussion section, and the ESI $\dagger$ ). NBO, ${ }^{63}$ Mulliken $^{64}$ and Bader ${ }^{65}$ partial charges were determined at the PBE0-D3(BJ)/def2-TVZPP//PBE0-D3(BJ)/ def2-TVZP level of sophistication, while the CM5M ${ }^{66}$ charges were obtained from ref. 37 .

The cross-correlated $R^{2}$ coefficient of correlation, $Q^{2}$, which was used in the statistical analysis, was evaluated by the leaveone-out procedure: ${ }^{67}$

$$
Q^{2}=1-\frac{\sum_{i=1}^{n}\left(y_{i}-\hat{y}\right)^{2}}{\sum_{i=1}^{n}\left(y_{i}-\bar{y}\right)^{2}}
$$

Above, $y_{i}$ is the $i$ th value of $y$ in the data series, $\bar{y}$ is the average value of $y$ over the data series whilst $\hat{y}_{i / i}$ is an estimated value of $y=y\left(x_{i}\right)$ determined from a linear regression analysis of the data series upon excluding the $i$ th data point.

\section{Results and discussion}

Our results are discussed in the following order: first we will give an overview of the general properties of the studied metal nanoparticles before studying the Lewis acidic and Lewis basic characteristics of the $\mathrm{Ag}_{9}$ nanoparticle in greater detail. This will be compared to the cases of the elementally isomeric $\mathrm{Cu}_{9}$ and $\mathrm{Au}_{9}$ nanoparticles. We will then proceed to assess the performance of the $V(\mathbf{r}), E(\mathbf{r})$ and $\bar{I}(\mathbf{r})$ descriptors compared to the results from a previous study of Duanmu et $a .^{37}{ }^{37}$ where site-resolved CO adsorption energies on $\mathrm{Ag}_{9}, \mathrm{Ag}_{11}, \mathrm{Ag}_{17}$ and $\mathrm{Ag}_{18}$ nanoparticles were correlated with partial atomic charges via the CM5M protocol. ${ }^{66}$

\subsection{Geometric and electronic structure of the nanoparticles}

The Ag nanoparticle structures were obtained from ref. 37. The $\mathrm{Ag}_{9}, \mathrm{Ag}_{11}, \mathrm{Ag}_{17}$ and $\mathrm{Ag}_{18}$ nanoparticles were re-optimized from the reported geometries while the $\mathrm{Au}_{9}$ and $\mathrm{Cu}_{9}$ nanoparticles were obtained by structural relaxation starting from the geometry of the $\mathrm{Ag}_{9}$ particle. $\mathrm{The}^{\mathrm{Ag}} \mathrm{g}_{9}$ (and hence $\mathrm{Cu}_{9}$ and $\mathrm{Au}_{9}$ ) and $\mathrm{Ag}_{11}$ structures are based on the $D_{5 \mathrm{~h}} \mathrm{Ag}_{7}$ structure, and formed by extending $\mathrm{Ag}_{7}$ with ad-atoms. $\mathrm{Ag}_{11}$ may, alternatively, be seen as two intertwined $\mathrm{Ag}_{7}$ structures. The $\mathrm{Ag}_{17}$ and $\mathrm{Ag}_{18}$ structures are based on an icosahedral $\mathrm{Ag}_{13}$ substructure. All particles have six or more non-equivalent adsorption sites including sites of three- to six-fold coordination. Over the series of $\mathrm{Ag}$ nanoparticles the average coordination number increases with the particle size. As can be seen in Table 1, the average distance between neighboring atoms is quite similar for the $\mathrm{Ag}$ particles. There is, however, a slight increase with particle size. For the elemental $\mathrm{M}_{9}(\mathrm{M}=\mathrm{Cu}, \mathrm{Ag}, \mathrm{Au})$ isomers, the $\mathrm{Au}_{9}$ and $\mathrm{Ag}_{9}$ particles are similar in size (similar average bond distances), while the 
Table 1 Geometrical and electronic data for the $\mathrm{Ag}, \mathrm{Cu}$ and $\mathrm{Au}$ nanoparticles

\begin{tabular}{llllllll}
\hline & $\begin{array}{l}\bar{d}_{\mathrm{M}-\mathrm{M}}{ }^{a} \\
{[\AA \AA}\end{array}$ & & & & & \\
& Sites $^{b}$ & $\bar{N}_{\text {coord }}{ }^{c}$ & $n_{\text {v-orb }}{ }^{d}\left[\begin{array}{l}\varepsilon_{\text {LUMO }} \\
{[\mathrm{eV}]}\end{array}\right.$ & $\begin{array}{l}\varepsilon_{\text {HOMO(SOMO) }}[\mathrm{eV}] \\
{[\mathrm{eV}]}\end{array}$ \\
\hline $\mathrm{Cu}_{9}$ & 2.48 & 7 & 4.67 & 22 & -3.70 & -4.46 & 0.76 \\
$\mathrm{Au}_{9}$ & 2.81 & 7 & 4.67 & 23 & -4.74 & -5.42 & 0.68 \\
$\mathrm{Ag}_{9}$ & 2.82 & 7 & 4.67 & 23 & -3.69 & -4.38 & 0.68 \\
$\mathrm{Ag}_{11}$ & 2.82 & 6 & 4.91 & 29 & -3.72 & -4.31 & 0.59 \\
$\mathrm{Ag}_{17}$ & 2.86 & 8 & 5.88 & 39 & -3.71 & -4.28 & 0.56 \\
$\mathrm{Ag}_{18}$ & 2.84 & 11 & 6.00 & 40 & -3.40 & -4.54 & 1.14
\end{tabular}

${ }^{a}$ Average distance between neighboring atoms. ${ }^{b}$ Number of nonequivalent on top adsorption sites. ${ }^{c}$ Mean coordination number of the particle surface atoms. ${ }^{d}$ Number of virtual spin orbitals below $\varepsilon=0$.

average bond distance in $\mathrm{Cu}_{9}$ is reduced by approximately $12 \%$ compared to $\mathrm{Ag}_{9}$ and $\mathrm{Au}_{9}$.

The structures of all of the studied nanoparticles are displayed in Fig. 2. $V_{\mathrm{S}}(\mathbf{r}), E_{\mathrm{S}}(\mathbf{r})$ and $\bar{I}_{\mathrm{S}}(\mathbf{r})$ determined on the 0.001 a.u. isodensity surfaces are also shown, as well as the valence electronic configuration (valence density of states - DOS). Corresponding figures of the HOMO (or, to be specific, the SOMO, singly occupied molecular orbital) and LUMO orbitals of $\mathrm{Ag}_{9}$ are displayed in Fig. 3. In addition, the HOMO (SOMO) and LUMO orbitals for the other particles are included in the ESI $\dagger$ along with a complete summary of all virtual orbitals used in the evaluation of $E_{\mathrm{S}}(\mathbf{r})$ for $\mathrm{Ag}_{9}$, i.e. all unoccupied orbitals of energy lower than the $E_{0}$ cut-off. The HOMO (SOMO) and LUMO energies can be found in Table 1. An analysis of the frontier orbitals alone is not sufficient to understand the NP interaction behavior (see ESI $\dagger$ ). This does not rule out orbital analysis as a tool per se; at the studied level of theory, $\mathrm{Ag}_{9}$ has 23 virtual spin orbitals below the free electron limit (see Table 1 and ESI $\dagger$ ). Many of these have energies similar to the LUMO but predict other preferred sites of interactions. Hence, although the use of the LUMO [and HOMOs(SOMOs)] for predicting interactions is limited for these systems, the general use of orbitals for understanding the reactivity is not; by considering the contributions of all relevant orbitals, a better representation is obtained as shown in the following discussion by the use of the $E(\mathbf{r})$ descriptor for local Lewis acidity, and by the $\bar{I}(\mathbf{r})$ descriptor in the case of Lewis basicity.

The $V_{\mathrm{S}}(\mathbf{r})$ and $E_{\mathrm{S}}(\mathbf{r})$ isodensity maps of Fig. 2 show that Lewis acidic sites (i.e. $V_{\mathrm{S} \text {,max }}$ sites $=\sigma$-holes) can be identified on top of all surface atoms using the $V_{\mathrm{S}}(\mathbf{r})$ probe, whereas in a few cases there is no local minimum in $E_{\mathrm{S}}(\mathbf{r})$ at the Lewis acidic site. The exceptions include the weak adsorption sites $\mathrm{Ag}_{9}(2), \mathrm{Ag}_{17}(1), \mathrm{Ag}_{17}(5), \mathrm{Ag}_{18}(1)$, $\mathrm{Ag}_{18}(2), \mathrm{Ag}_{18}(6), \mathrm{Ag}_{18}(7)$ and $\mathrm{Ag}_{18}(8)$. For these sites, the local value of $E_{\mathrm{S}}(\mathbf{r})$ at the "on top" site that coincides approximately with the intersection between the particle-adsorbate bond and the isosurface has been used in the interaction analysis. From the $V_{\mathrm{S}}(\mathbf{r})$ map we can further identify Lewis basic sites (i.e. $V_{\mathrm{S} \text {,min }}$ sites $=$ $\sigma$-lumps) at bridge and hollow sites formed in-between the atoms of the particle. A more detailed analysis of the Lewis acidic and basic properties of $\mathrm{Ag}_{9}$ follows in Section 3.2 below.

\subsection{Lewis acidity and basicity of $\mathbf{A g}_{9}$}

In the following we will elaborate on the details of the local interaction properties of $\mathrm{Ag}_{9}$. This will serve as a prototypical example of the applicability and conceptual transparency of the considered descriptors. Similar analyses are performed in full or in part for the other particles used in the present study (see discussion further below and in the ESI $\dagger$ ). Fig. 3 shows how the Lewis basic and acidic character of $\mathrm{Ag}_{9}$ varies over the 0.001 a.u. isosurface from the perspective of the $V_{\mathrm{S}}(\mathbf{r}), E_{\mathrm{S}}(\mathbf{r}), \bar{I}_{\mathrm{S}}(\mathbf{r})$ properties. In addition, the HOMO (SOMO) and LUMO orbitals are included in the figure for comparison. The reader will now recall that the electrostatic potential $V_{\mathrm{S}}(\mathbf{r})$ is able to identify both Lewis acidic (local maxima) and Lewis basic (minima) sites, while minima in $E_{\mathrm{S}}(\mathbf{r})$ mark Lewis acidic sites and minima in $\bar{I}_{\mathrm{S}}(\mathbf{r})$ mark Lewis basic sites, respectively.

General overview. From $V_{\mathrm{S}}(\mathbf{r})$ we find areas of high Lewis acidity ( $\sigma$-holes) straight above (on top) of all the Ag atoms, indicating that these sites are the favored positions for electrostatically driven interactions with electron donating molecules. Similarly $E_{\mathrm{S}}(\mathbf{r})$ locates Lewis acidic sites at the on top sites, but in some cases, e.g. $\mathrm{Ag}_{9}(5)$, the minima $\left(E_{\mathrm{S}, \mathrm{min}}\right)$ are not positioned straight above the atoms with respect to the center of gravity of the cluster, but at a slightly tilted angle. For the $\mathrm{Ag}_{9}(2)$ site there is no local minimum in $E_{\mathrm{S}}(\mathbf{r})$. For the comparison with other adsorption sites, the $E_{\mathrm{S}}(\mathbf{r})$ value at the on top site straight above the $\mathrm{Ag}_{9}(2)$ atom will be used in the following (i.e. approximately the site of the intersection of the adsorbate NP bond and the isosurface). $V_{\mathrm{S}}(\mathbf{r})$ ranks the Lewis acidity of the unique, nonequivalent, sites as $\mathrm{Ag}_{9}(4)>\mathrm{Ag}_{9}(8)>\mathrm{Ag}_{9}(9)>\mathrm{Ag}_{9}(3)>\mathrm{Ag}_{9}(5)>$ $\mathrm{Ag}_{9}(1)>\mathrm{Ag}_{9}(2)$, whereas for $E_{\mathrm{S}}(\mathbf{r})$ the order of the $\mathrm{Ag}_{9}(8)$ and $\mathrm{Ag}_{9}(9)$ sites is interchanged. Note that this difference cannot be visualized in Fig. 3, since the red color of the sites only means that, e.g., the potential is larger than $325 \mathrm{meV}$. As concerning Lewis basicity, areas of low electrostatic potential (indicative of $\sigma$-lumps) are found in between the Lewis basic atoms at bridge and hollow sites. The same general areas also correspond to local minima in $\bar{I}_{\mathrm{S}}(\mathbf{r})$, although $\bar{I}_{\mathrm{S}}(\mathbf{r})$ also attributes some Lewis basicity to $\mathrm{Ag}(9)$ on top sites. From the analysis of minima in $V_{\mathrm{S}}(\mathbf{r})$ and $\bar{I}_{\mathrm{S}}(\mathbf{r})$ there are two Lewis basic areas of special importance. These are the sites that should be most prone to interactions with electron-acceptors and are located at opposite sides of the $\mathrm{b}_{58}$ bridge formed between $\mathrm{Ag}_{9}(5)$ and $\mathrm{Ag}_{9}(8)$ : one area encompasses the two hollow sites $h_{135}$ and $h_{158}$ formed in between the $\mathrm{Ag}_{9}(1), \mathrm{Ag}_{9}(3)$ and $\mathrm{Ag}_{9}(5)$ atoms as well as the $\mathrm{Ag}_{9}(1), \mathrm{Ag}_{9}(5)$ and $\mathrm{Ag}_{9}(8)$ atoms; the other area encompasses the $\mathrm{h}_{245}$ and $\mathrm{h}_{258}$ hollow sites. Other significant Lewis basic areas are identified at the $h_{178}, h_{345}$ and $h_{789}$ sites. The local minima in both $V_{\mathrm{S}}(\mathbf{r})$ and $\bar{I}_{\mathrm{S}}(\mathbf{r})$ rank the Lewis basic sites of $\mathrm{Ag}_{9}$ as $\mathrm{h}_{135} / \mathrm{h}_{158}>\mathrm{h}_{245} / \mathrm{h}_{258}>\mathrm{h}_{178}>\mathrm{h}_{345}>\mathrm{h}_{789}$. The bridge sites do not correspond to local minima in $V_{\mathrm{S}}(\mathbf{r})$ and $\bar{I}_{\mathrm{S}}(\mathbf{r})$, but are instead Lewis acidic saddle points. These could potentially act as the site of interaction given a suitable adsorbent. We did e.g. find that $\mathrm{H}^{+}$preferentially adsorbs at bridge sites.

Lewis acidity predictions. Now to the critical question: how do the predictions from the descriptors correlate with the chemical interactions of $\mathrm{Ag}_{9}$ ? In the lack of high-quality experimental data to compare with, we have created a small computational reference data set comprising interactions with both electron donating and accepting probe molecules as specified 

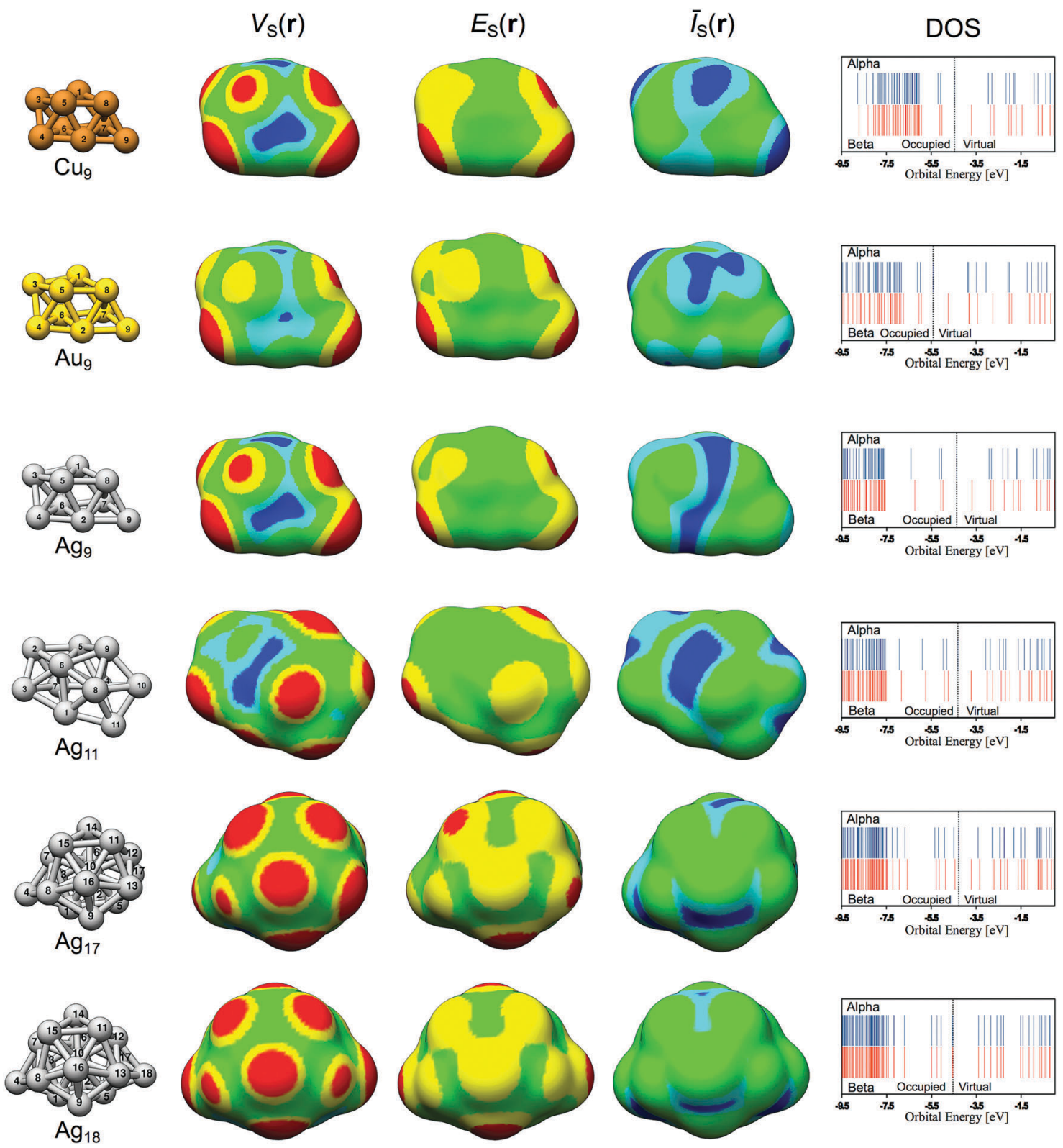

Fig. 2 Overview of the Lewis acidic and basic properties of the $\mathrm{Cu}_{9}, \mathrm{Au}_{9}, \mathrm{Ag}_{9}, \mathrm{Ag}_{11}, \mathrm{Ag}_{17}$ and $\mathrm{Ag}_{18}$ nanoparticles. The $V_{\mathrm{S}}(\mathbf{r}), E_{\mathrm{S}}(\mathbf{r})$ and $\bar{l}_{\mathrm{S}}(\mathbf{r})$ quantities are evaluated on the 0.001 a.u. isodensity surface. Color code for $V_{S}(\mathbf{r})$ in meV: red $>325 ; 150<$ yellow $<325 ;-150<$ green $<150$; $-325<$ cyan $<-150$; blue $<-325$. $E_{S}(\mathbf{r})$ in eV: red $<-8.0<$ yellow $<-6.0<$ green. $\bar{I}_{S}(\mathbf{r})$ have different color codes for the different metals, in eV; Cu: blue $<5.8<$ cyan $<5.9<$ green; Ag: blue $<6.1<$ cyan $<6.3<$ green; Au: blue $<7.2<$ cyan $<7.5<$ green. The DOS entries show to the electronic valence structure.

in the computational methods. Beginning with the Lewis acidity of $\mathrm{Ag}_{9}$, we find that the sites identified by $V_{\mathrm{S}}(\mathbf{r})$ and $E_{\mathrm{S}}(\mathbf{r})$ coincide with the predicted adsorption sites of electron donating molecules. These include the $\mathrm{H}_{2} \mathrm{O}, \mathrm{NH}_{3}, \mathrm{H}_{2} \mathrm{~S}$ and $\mathrm{CO}$ molecules that have varying Lewis acidic characteristics as shown in Table 2. If we first consider the electrostatic properties of these compounds, the magnitude of the $V_{\mathrm{S} \text {,min }}$ ( $\sigma$-lumps) located at the interacting atom ranks the molecules as $\mathrm{NH}_{3}>$ $\mathrm{H}_{2} \mathrm{O}>\mathrm{H}_{2} \mathrm{~S}>\mathrm{CO}$. Thus if the $\mathrm{Ag}_{9}$ interactions are purely electrostatic we expect the interaction strength to be ranked in the same order. However, the calculated average interaction energies are ordered as $\mathrm{NH}_{3}>\mathrm{CO}>\mathrm{H}_{2} \mathrm{~S}>\mathrm{H}_{2} \mathrm{O}$. In a similar manner, $\bar{I}_{\mathrm{S} \text {,min }}$ can be used to estimate the charge-transfer/ polarization capacities of the probe molecules. This ranks them as $\mathrm{NH}_{3}>\mathrm{H}_{2} \mathrm{~S}>\mathrm{H}_{2} \mathrm{O}>\mathrm{CO}$, with the same ordering being expected for the interaction energies if charge-transfer and polarization effects dominate the interactions. Again this does not follow the calculated interaction energy trend. In summary the results suggest that some or all of the interactions have interaction modes that are not purely electrostatically or chargetransfer/polarization controlled. For mixed interaction modes it has previously been shown that combined dual-relationships of $V_{\mathrm{S} \text {, min }}$ and $\bar{I}_{\mathrm{S} \text {, min }}$ give a good description for trends in the relative interaction strength. ${ }^{28,68}$ This approach has been found 


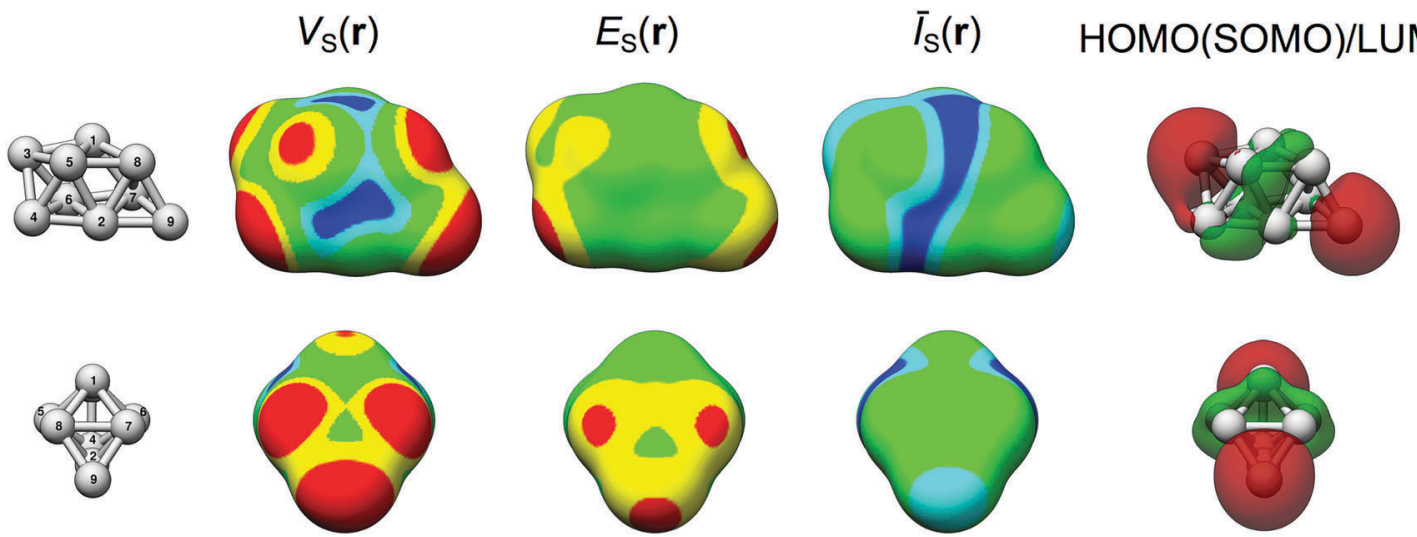

Fig. $3 V_{S}(\mathbf{r}), E_{S}(\mathbf{r}), T_{S}(\mathbf{r})$ at the 0.001 a.u. isodensity surface as well as the LUMO and HOMO (SOMO) orbitals of $\mathrm{Ag}_{9}$. Color code $V_{S}(\mathbf{r})$ in meV: red $>325$; $150<$ yellow $<325 ;-150<$ green $<150 ;-325<$ cyan $<-150$; blue $<-325$. $E_{\mathrm{S}}(\mathbf{r})$ in eV: red $<-8.0<$ yellow $<-6.0<$ green. $\bar{I}_{\mathrm{S}}(\mathbf{r})$ in eV: blue $<$ $6.1<$ cyan < $6.3<$ green. The HOMO (SOMO) and LUMO orbitals are differentiated by different spin phases (not indicated in figure) with only minor spatial differences.

Table 2 Adsorption distances $(d)$ in $\AA$, average interaction energies $\left(\Delta \bar{E}_{\text {int }}\right)$ in kcal mol ${ }^{-1}$, and charge-transfer information for the $C \mathrm{C}, \mathrm{H}_{2} \mathrm{O}, \mathrm{NH}_{3}$, and $\mathrm{H}_{2} \mathrm{~S}$ Lewis bases and $\mathrm{BH}_{3}, \mathrm{BF}_{3}, \mathrm{HCl}\left(\mathrm{H}\right.$-down), and $\mathrm{Na}^{+}$Lewis acids onto $\mathrm{Ag}_{9}$. Additional information is provided in the ESI. $V_{\mathrm{S}, \min }$ and $V_{\mathrm{S}, \max }$ in $\mathrm{kcal}$ mol ${ }^{-1}$, and $\bar{I}_{\mathrm{S}, \min }$ and $E_{\mathrm{S}, \min }$ in $\mathrm{eV}$, are given on the 0.001 a.u. isosurface at the site of interactions for the Lewis bases and Lewis acids, respectively

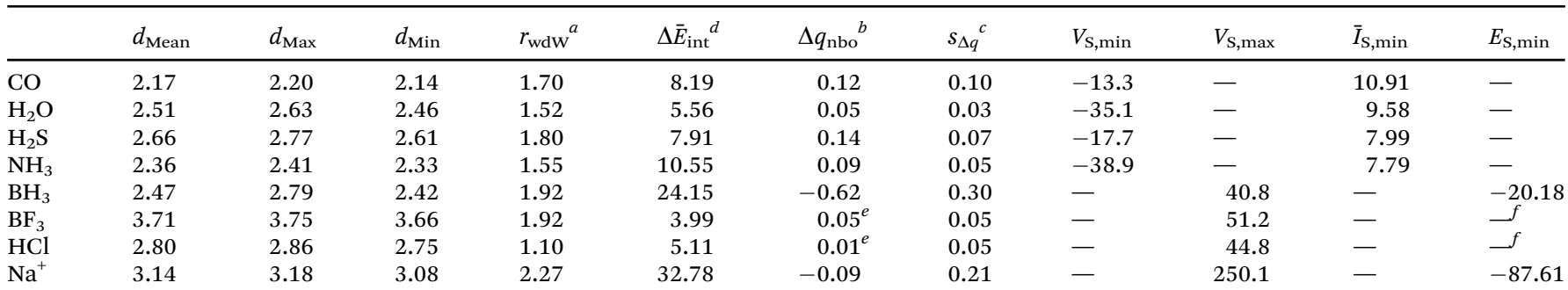

${ }^{a}$ van der Waals radius of the interacting atoms, i.e. $\mathrm{C}, \mathrm{O}, \mathrm{S}, \mathrm{N}, \mathrm{B}, \mathrm{B}, \mathrm{H}$, and $\mathrm{Na},{ }^{75}$ the Bondi van der Waals radii of Ag is $1.72 .{ }^{76}{ }^{b}$ Average chargetransfer in a.u. upon particle-Lewis base interactions evaluated by NBO charges. ${ }^{c}$ Pooled variance in the atomic partial charge for each interaction over the series. ${ }^{d}$ Obtained at the PBE0-D3(BJ)/def2-TVZPP//PBE0-D3(BJ)/def2-TVZP level of theory. ${ }^{e}$ Note that the NBO analysis suggests that BF 3 and $\mathrm{HCl}$ donate electrons to $\mathrm{Ag}_{9}$, although they interact via a Lewis basic adsorption mode at the hollow sites. ${ }^{f}$ Could not be determined since no virtual orbital with $\varepsilon<0$.

especially useful in understanding the interaction behavior of molecules spanning over different groups and periods of the periodic table. This will be discussed in the following paragraphs and returned to in Section 3.3 as it turns out that comparison between different substrate NPs benefits the analysis. Table 2 summarizes the geometrical details of the $\mathrm{H}_{2} \mathrm{O}, \mathrm{NH}_{3}$, $\mathrm{H}_{2} \mathrm{~S}$ and $\mathrm{CO}$ adsorption onto $\mathrm{Ag}_{9}$, and Fig. 6 shows the lowest energy adsorption structures of $\mathrm{CO}, \mathrm{H}_{2} \mathrm{O}, \mathrm{H}_{2} \mathrm{~S}, \mathrm{NH}_{3}$, and $\mathrm{CO}$.

We will begin the analysis by discussing $\mathrm{H}_{2} \mathrm{O}$ and $\mathrm{NH}_{3}$. These are well-behaved probe molecules for evaluation of local Lewis acidity since both $\mathrm{H}_{2} \mathrm{O}$ and $\mathrm{NH}_{3}$ interact via a single atom $(\mathrm{O} / \mathrm{N}$-down) by donation of an electron lone pair without altering the probe molecules or the $\mathrm{Ag}_{9}$ substrate's structure significantly. As described in the Introduction section, this kind of interaction between a noble metal NP $\sigma$-hole and an electron donor will henceforth be referred to as a regium bond. The computed regium bond energies of $\mathrm{H}_{2} \mathrm{O}$ and $\mathrm{NH}_{3}$ for each unique site of $\mathrm{Ag}_{9}$ follow the order predicted by $V_{\mathrm{S}}(\mathbf{r})$ with a coefficient of determination $\left(R^{2}\right)$ of $0.971\left(\mathrm{H}_{2} \mathrm{O}\right)$ and $0.961\left(\mathrm{NH}_{3}\right)$. This is with respect to the local $V_{\mathrm{S}, \max }$ values determined on the 0.001 a.u. isodensity surface at the sites of interaction.
The corresponding $R^{2}$-coefficents for $E_{\mathrm{S} \text {,min }}$ are slightly higher, 0.989 and 0.987 for $\mathrm{H}_{2} \mathrm{O}$ and $\mathrm{NH}_{3}$, respectively (see Fig. 4).

From this isolated comparison one could conclude that $E_{\mathrm{S}}(\mathbf{r})$ and $V_{\mathrm{S}}(\mathbf{r})$ describe the interactions similarly well and it is difficult to assign the relative charge-transfer/polarization and electrostatic character of the interaction. We can also note that $V_{\mathrm{S}, \max }$ and $E_{\mathrm{S}, \min }$ mutually correlate with an $R^{2}$ value of 0.984 . Upon closer analysis it is, however, found that the positions of $V_{\mathrm{S}, \max }$ better coincide with the adsorption geometries of $\mathrm{NH}_{3}$ and $\mathrm{H}_{2} \mathrm{O}$. This can be observed e.g. for position 5 of Ag $_{9}$ (Fig. 3), or from the fact that there is no local minimum in $E_{\mathrm{S}}(\mathbf{r})$ for position 2, which argues for a larger portion of electrostatic control in the interactions. From HSAB theory ${ }^{21}$ it is known that both $\mathrm{H}_{2} \mathrm{O}$ and $\mathrm{NH}_{3}$ are considered hard electron donors (Lewis bases); this means that their interactions are expected to be dominated by electrostatics, and not by charge-transfer/ polarization. The $\mathrm{H}_{2} \mathrm{~S}$ molecule is located on the other (soft) end of the HSAB scale. We hence expect the regium bonds between the $\mathrm{H}_{2} \mathrm{~S}$ molecule and $\mathrm{Ag}_{9}$ to include a larger portion of charge-transfer/polarization. However, it turns out that $V_{\mathrm{S}}(\mathbf{r})$ and $E_{\mathrm{S}}(\mathbf{r})$ give similar correlations with the $\mathrm{H}_{2} \mathrm{~S}$ interaction 

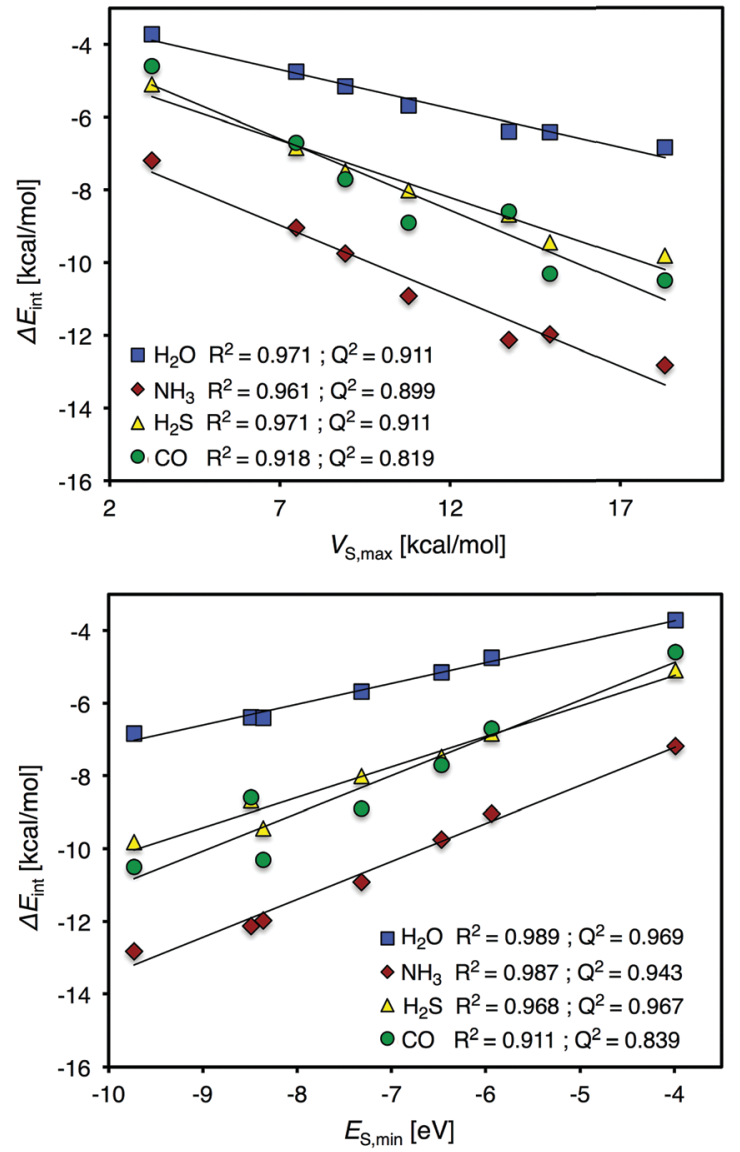

Fig. $4 V_{S, \max }$ (top) and $E_{S, \text { min }}$ (bottom) values versus local interaction energies of the $\mathrm{H}_{2} \mathrm{O}, \mathrm{NH}_{3}, \mathrm{H}_{2} \mathrm{~S}$ and $\mathrm{CO}$ electron donors at the seven unique sites of $\mathrm{Ag}_{9} . V_{\mathrm{S}, \max }$ and $E_{\mathrm{S}, \min }$ were evaluated at the 0.001 a.u. isodensity surface.

energy as with the $\mathrm{H}_{2} \mathrm{O}$ and $\mathrm{NH}_{3}$ interaction energies. In addition, $V_{\mathrm{S}}(\mathbf{r})$ shows an equally strong correlation with $\mathrm{H}_{2} \mathrm{~S}$ adsorption as $E_{\mathrm{S}}(\mathbf{r}): R^{2}=0.971$ and 0.968 , respectively. Hence, at this point we cannot draw any definitive conclusions regarding electrostatics compared to charge-transfer/polarization effects. It can, nevertheless, be concluded that the interactions are not purely electrostatic since the average interaction energies of the probe molecules (including also $\mathrm{CO}$, vide infra) do not follow the ranking of $V_{\mathrm{S}, \min }$ of the molecules (Table 2). The comparison between electrostatics and charge-transfer/polarization will be further discussed in connection to the interactions of the $\mathrm{Au}_{9}$ and $\mathrm{Cu}_{9} \mathrm{NP}$ of the Section 3.3.

A general conclusion from this study is that the correlation, or the lack of correlation, between descriptor values and interaction energies can partly be explained by the amount of charge-transfer; from NBO analysis we find an inverted correlation between the $R^{2}$-values for the different series and amounts of charge-transfer $\Delta q_{\text {nbo }}$ (see Table 2 and the ESI $\dagger$ ). An even stronger inversed trend is found between $R^{2}$-vaules for the different series and the variance of the charge-transfer within the series. Taken together, this suggests that the predictive power of the ground-state descriptors $V_{\mathrm{S}}(\mathbf{r})$ and $E_{\mathrm{S}}(\mathbf{r})$ suffers the more the electronic structure of the ground state is altered by the interactions. The implication is that soft interactions are more difficult to describe than hard interactions since these by nature cause a larger deviation from the ground state. Similarly, and also as a general conclusion, we find that the more the geometries of the adsorbate and NP are distorted upon interactions, the weaker are the correlations between interaction energies and the descriptor values (see the ESI $\dagger$ ). In addition to the above, some deviation between descriptor predictions and computed interaction energies is expected since the descriptors do not directly reflect dispersion effects or vibrational energy contributions.

The interactions of $\mathrm{CO}$ with the $\mathrm{Ag}_{9}$ have previously been studied by Duanmu et al. ${ }^{37}$ Although we will here treat $\mathrm{CO}$ as a Lewis base, the CO molecule is known to be an ambivalent adsorbate with a mode of interaction that is characterized by both electron donation from $\mathrm{CO}$ and back-donation from the substrate as a result of a repulsive $\sigma$-interaction and constructive $\pi$-orbital overlap, ${ }^{69-72}$ i.e. CO acts as both a Lewis base and, to some degree, a Lewis acid. Upon interactions with metal surfaces it has, moreover, been found that $\mathrm{CO}$ undergoes a substantial valence orbital rehybridization. ${ }^{73,74}$ The density difference plots obtained for $\mathrm{H}_{2} \mathrm{O}, \mathrm{H}_{2} \mathrm{~S}, \mathrm{NH}_{3}$, and CO adsorption are shown in Fig. 5 illustrating the different interaction modes where $\mathrm{CO}$ adsorption leads to a constructive orbital overlap leading to a buildup of electron density; this is indicative of a covalent bond, whereas $\mathrm{H}_{2} \mathrm{O}, \mathrm{H}_{2} \mathrm{~S}$ and $\mathrm{NH}_{3}$ adsorption instead polarizes the charge densities of the interacting species. The latter suggests an electrostatic interaction enhanced by polarization rather than a charge-transfer complex. On the other hand the interactions with all Lewis bases result in adsorption distances considerably shorter than the sum of the van der Waals radii of the interacting atoms, which suggest interactions stronger than van der Waals interactions. Furthermore, as discussed above, there is no correlation between the average interaction energy and $V_{\mathrm{S}, \min }$ of the Lewis bases, where, e.g., $\mathrm{H}_{2} \mathrm{~S}$ binds stronger than $\mathrm{H}_{2} \mathrm{O}$.

Given the complex nature of the $\mathrm{CO}$ interaction it is expected that neither $V_{\mathrm{S}, \max }$ nor $E_{\mathrm{S} \text {,min }}$ will fully capture the interaction by itself. Indeed, among the considered adsorbates the CO interaction energy displays the weakest correlation with respect
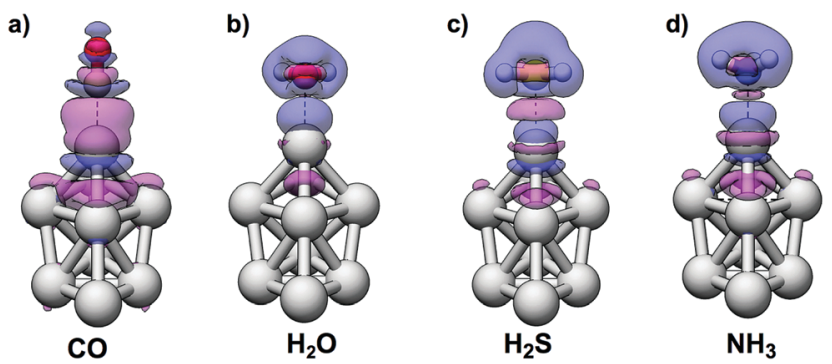

Fig. 5 Density difference plots at the 0.00075 a.u. contours for (a) $\mathrm{CO}$, (b) $\mathrm{H}_{2} \mathrm{O}$, (c) $\mathrm{H}_{2} \mathrm{~S}$ and (d) $\mathrm{NH}_{3}$ adsorption onto atomic site 4 of $\mathrm{Ag}_{9}$. Color: purple $=$ density accumulation, blue $=$ density depletion. The figures are obtained at the optimized adsorbate structures by subtraction of the individual densities of $\mathrm{Ag}_{9}$ and the adsorbate, with frozen coordinates, from the total density of the $\mathrm{Ag}_{9}$-adsorbate complex. 

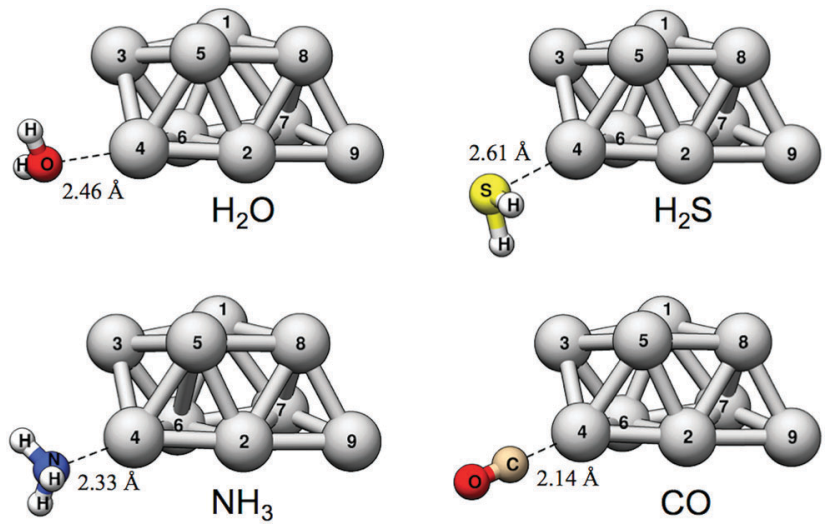

Fig. 6 The favored adsorption structures for the $\mathrm{H}_{2} \mathrm{O}, \mathrm{H}_{2} \mathrm{~S}, \mathrm{NH}_{3}$ and $\mathrm{CO}$ Lewis bases onto $\mathrm{Ag}_{9}$

to the descriptor values $\left[R^{2}=0.918\right.$ for $V_{\mathrm{S}}(\mathbf{r})$ and 0.911 for $\left.E_{\mathrm{S}}(\mathbf{r})\right]$. Nonetheless, these correlations are significantly better than those obtained by Duanmu et al. ${ }^{37}$ based on $\mathrm{CM}_{5} \mathrm{M}^{66}$ partial atomic charges $\left(R^{2}=0.74\right)$. The comparison between the $V_{\mathrm{S}}(\mathbf{r})$ and $E_{\mathrm{S}}(\mathbf{r})$ descriptors and partial charges for $\mathrm{CO}$ interactions will be discussed further in Section 3.4.

Lewis basicity. In order to probe the local Lewis basicity of $\mathrm{Ag}_{9}$ we have studied adsorption of the $\mathrm{BH}_{3}, \mathrm{BF}_{3}, \mathrm{Na}^{+}$and $\mathrm{HCl}$ (via the H-down adsorption mode) electron-acceptors. All sites, including the on top, bridge and hollow sites, were considered. The adsorption structures primarily converged to the hollow $\mathrm{h}_{135}$, $\mathrm{h}_{158}, \mathrm{~h}_{245}, \mathrm{~h}_{258}, \mathrm{~h}_{178}, \mathrm{~h}_{345}$ and $\mathrm{h}_{789}$ sites, but also in some few cases to the $b_{13}, b_{34}$ and $b_{89}$ sites. In line with the predictions by the descriptors, the $\mathrm{h}_{135} / \mathrm{h}_{158}$ and $\mathrm{h}_{245} / \mathrm{h}_{258}$ regions correspond to the largest interaction energies for all of the considered electronacceptors. While the qualitative picture obtained by $V_{\mathrm{S}}(\mathbf{r})$ and $\bar{I}_{\mathrm{S}}(\mathbf{r})$ is clearly correct, the correlations between local descriptor values at the 0.001 a.u. isosurface and interaction energies are weaker than those found for local Lewis acidity. For $V_{\mathrm{S}, \min }$ we find $R^{2}$-values of $0.659\left(\mathrm{BH}_{3}\right), 0.922\left(\mathrm{BF}_{3}\right), 0.950\left(\mathrm{Na}^{+}\right)$and 0.821 ( $\mathrm{HCl})$ when considering the hollow site adsorption. For $\bar{I}_{\mathrm{S}}(\mathbf{r})$ the corresponding values are $0.768\left(\mathrm{BH}_{3}\right), 0.835\left(\mathrm{BF}_{3}\right), 0.901\left(\mathrm{Na}^{+}\right)$and $0.695(\mathrm{HCl})$. The good performance of $V_{\mathrm{S}}(\mathbf{r})$ for $\mathrm{Na}^{+}$indicates primarily electrostatic interactions between $\mathrm{Ag}_{9}$ and the $\mathrm{Na}^{+}$cation. The weak correlations for the other electron-accepting adsorbents reveal a more complex interaction compared to interactions of the electron-donating molecules (e.g. $\mathrm{H}_{2} \mathrm{O}$ ). For instance, $\mathrm{BH}_{3}$ not only interacts via the $\mathrm{B}$ atom but also via its $\mathrm{H}$ atoms, which are eclipsing adjacent $\mathrm{Ag}$ atoms. In addition $\mathrm{BH}_{3}$ (planar structure as unbound) is bent upon interaction with $\mathrm{Ag}_{9}$. This adds further complexity to the analysis. However, by forming a linearcombination between $\bar{I}_{\mathrm{S}, \min }$ at the site of the B atom interaction and the sum of $V_{\mathrm{S}, \max }$ at the $\mathrm{H}$-accepting Ag on top sites, a correlation with an $R^{2}$ value of 0.982 is obtained. This indicates that more information is needed to describe this particular interaction compared to, e.g. the interaction with $\mathrm{H}_{2} \mathrm{O}$. $\|$ Similar arguments

|| It should, nevertheless, be noted that only five points are used in the multi-linear regression, which in-fact is not a sufficient number for a proper analysis.
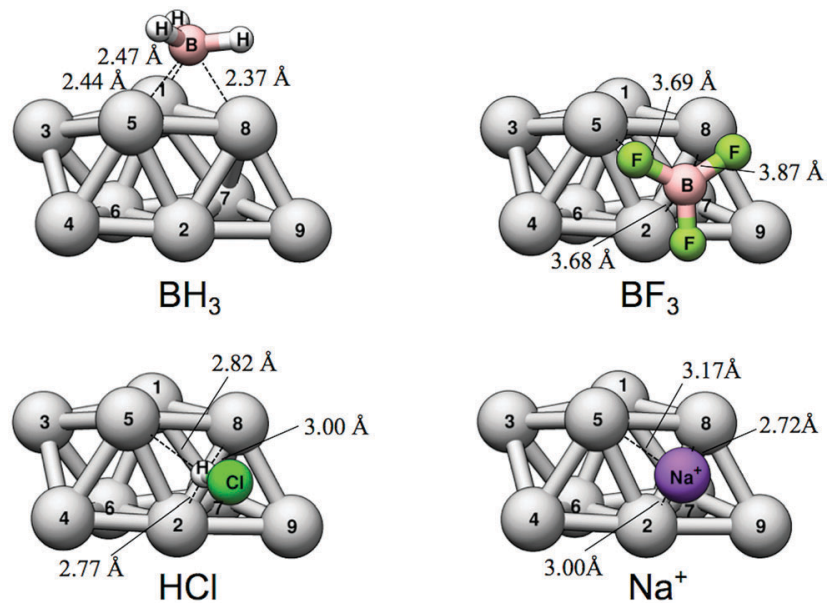

Fig. 7 The favored adsorption structures for the $\mathrm{BH}_{3}, \mathrm{BF}_{3}, \mathrm{Na}^{+}$and $\mathrm{HCl}$ ( $\mathrm{H}$-down) electron-acceptors onto $\mathrm{Ag}_{9}$. Note that $\mathrm{BH}_{3}$ favors the $\mathrm{h}_{158}$ site while the remaining compounds prefer the $h_{238}$ site. The depicted bond distances correspond to those between the central atom of the adsorbent and the adjacent $\mathrm{Ag}_{9}$ atoms.

can be invoked for $\mathrm{BF}_{3}$. However, the effects are smaller since $\mathrm{BF}_{3}$ forms weaker bonds with the $\mathrm{Ag}_{9}$ nanoparticles than $\mathrm{BH}_{3}$. The geometrical details for the electron-acceptors, including average adsorption distances and interaction energies, are summarized in Table 2. Fig. 7 shows the lowest energy adsorption structures for the various probe molecules' interactions with $\mathrm{Ag}_{9}$.

Similar to the case of Lewis base adsorption, we can employ local descriptor values (the $V_{\mathrm{S}, \max }$ and $E_{\mathrm{S} \text {, min }}$ ) at the central interacting atom of the probe molecules to better understand the nature of the interaction. We did, for instance, find that $E_{\mathrm{S}, \min }$ could not be determined on either $\mathrm{HCl}$ or $\mathrm{BF}_{3}$ since, at the considered level of theory, they do not have virtual orbitals of negative eigenvalues. Consequently the contribution from chargetransfer to the Lewis acidity is expected to be small, which is corroborated by a NBO analysis (Table 2). Moreover, the relative interaction energies do not follow the ranking of $V_{\mathrm{S}, \max }$ of the Lewis acids. Again this underlines that the interactions of (some of) the Lewis acids are more complex and not dominated by electrostatics. An interesting observation in connection to this is that in the case of $\mathrm{BH}_{3}, \mathrm{NBO}$ analysis shows a large charge-transfer of around $0.6 \mathrm{e}^{-}$from $\mathrm{Ag}_{9}$ to $\mathrm{BH}_{3}$. Hence the strong charge-transfer interaction compensates for its comparable small electrostatic driving force giving rise to a comparably strong overall interaction.

\subsection{Lewis acidity of $\mathrm{Au}_{9}, \mathrm{Ag}_{9}$ and $\mathrm{Cu}_{9}$}

As shown above, clearly $V_{\mathrm{S}}(\mathbf{r}), E_{\mathrm{S}}(\mathbf{r})$ and $\bar{I}_{\mathrm{S}}(\mathbf{r})$ reflect the interaction behavior of the $\mathrm{Ag}_{9}$ nanoparticle. However, are these descriptors able to capture trends also for other group 11 NPs? This will be investigated by comparing the Lewis acidity of the three elemental isomers $\mathrm{Cu}_{9}, \mathrm{Ag}_{9}$ and $\mathrm{Au}_{9}$ probed by $\mathrm{H}_{2} \mathrm{O}$ and $\mathrm{H}_{2} \mathrm{~S}$ adsorption. Since we are here focusing on Lewis acidity, only the $V_{\mathrm{S}}(\mathbf{r})$ and $E_{\mathrm{S}}(\mathbf{r})$ descriptors will be considered.

Apart from the fact that the $\mathrm{Cu}$ particle is considerably smaller in comparison to the other particles, $\mathrm{Au}_{9}, \mathrm{Ag}_{9}$ and $\mathrm{Cu}_{9}$ are 
structurally identical. The similarities are reflected in the $V_{\mathrm{S}}(\mathbf{r})$ and $E_{\mathrm{S}}(\mathbf{r})$ isodensity maps shown in Fig. 2 that display a close resemblance between the particles. The $V_{\mathrm{S}}(\mathbf{r})$ and $E_{\mathrm{S}}(\mathbf{r})$ maps indicate that the on top sites are Lewis acidic centers also for the $\mathrm{Au}$ and $\mathrm{Cu}$ particles. Accordingly, adsorption of $\mathrm{H}_{2} \mathrm{O}$ and $\mathrm{H}_{2} \mathrm{~S}$ takes place on top of the atomic positions also for the $\mathrm{Au}$ and $\mathrm{Cu}$ particles. The average binding distances for $\mathrm{H}_{2} \mathrm{O}$ are $2.17 \pm 0.11 \AA$ for $\mathrm{Cu}_{9}, 2.47 \pm 0.15 \AA$ for $\mathrm{Ag}_{9}$, and $2.51 \pm 0.12 \AA$ for $\mathrm{Au}_{9}$. On the average, $\mathrm{H}_{2} \mathrm{O}$ adsorbs strongest onto the $\mathrm{Cu}$ particle by $-7.4 \mathrm{kcal} \mathrm{mol}^{-1}$, by $-6.2 \mathrm{kcal} \mathrm{mol}^{-1}$ and $5.6 \mathrm{kcal} \mathrm{mol}^{-1}$ onto $\mathrm{Au}_{9}$ and $\mathrm{Ag}_{9}$ respectively. $\mathrm{H}_{2} \mathrm{~S}$ adsorbs at the same sites but here $\mathrm{Au}_{9}$ displays the strongest average interactions (-14.8 $\left.\mathrm{kcal} \mathrm{mol}^{-1}\right)$ followed by $\mathrm{Cu}_{9}$ and $\mathrm{Ag}_{9}\left(-10.2\right.$ and $\left.-7.9 \mathrm{kcal} \mathrm{mol}^{-1}\right)$. Upon interaction between $\mathrm{Au}_{9}$ and $\mathrm{H}_{2} \mathrm{~S}$, the particle geometry is largely distorted. This is a reflection of the well-known fluxionality (i.e. geometric adaptability) of Au NPs, a feature that is often acknowledged as an important factor for the high catalytic activity of $\mathrm{Au}$ NPs. ${ }^{77}$ Due to the large geometric rearrangement upon the $\mathrm{H}_{2} \mathrm{~S}-\mathrm{Au}_{9}$ interactions, the $\mathrm{Au}_{9}$ atoms were constraint at their original positions during optimization of the adsorption structures in order to facilitate the analysis of the correlation between descriptor values and interaction energies.

Fig. 8 shows that the trend in $\mathrm{H}_{2} \mathrm{O}$ interaction energies of the particles closely follows the variations of the relative magnitude of both $V_{\mathrm{S} \text {,max }}$ and $E_{\mathrm{S} \text {,min }}$ on the 0.001 a.u. isosurface for all the nanoparticles. For $\mathrm{H}_{2} \mathrm{O}$ adsorption, $E_{\mathrm{S} \text {, min }}$ gives similar correlations for all three particles with $R^{2} \approx 0.985$, whereas $V_{\mathrm{S}, \max }$ gives slightly weaker correlations for $\mathrm{Au}$ and $\mathrm{Cu}\left(R^{2} \approx 0.950\right)$ compared to $\mathrm{Ag}_{9}\left(R^{2}=0.971\right)$. We can, moreover, note that $\mathrm{H}_{2} \mathrm{O}$ and $\mathrm{Cu}_{9}$ form the strongest interaction amongst the nanoparticles. This is well-reflected by the electrostatic potential since $\mathrm{Cu}_{9}$ has the largest $V_{\mathrm{S} \text {,max }}$ of the particles. $E_{\mathrm{S}, \min }$ does, on the other hand, predict the $\mathrm{Au}_{9}$ nanoparticle as the most reactive, which instead is in-line with the $\mathrm{H}_{2} \mathrm{~S}$ adsorption energies. It is interesting to note that the $\mathrm{Cu}$ particle, which is considered a harder metal than $\mathrm{Au}$, forms the strongest bonds to the hard $\mathrm{H}_{2} \mathrm{O}$ adsorbate, while the soft $\mathrm{Au}_{9}$ forms the strongest bonds with the soft $\mathrm{H}_{2} \mathrm{~S}$ adsorbate. As concerning the $\mathrm{H}_{2} \mathrm{~S}$ correlations, the $\mathrm{Au}_{9}-\mathrm{H}_{2} \mathrm{~S}$ interaction gives comparable poor $R^{2}$ values of 0.856 for $V_{\mathrm{S} \text {,max }}$ and 0.916 for $E_{\mathrm{S} \text {,min }}$ on the 0.001 a.u. isosurfaces, respectively (see Fig. 8). This can be attributed to a large charge-transfer/ polarization effect upon $\mathrm{H}_{2} \mathrm{~S}$ adsorption leading to a redistribution of the electronic structures, which is a reflexing of the large tendency for structural changes of $\mathrm{Au}_{9}$ upon $\mathrm{H}_{2} \mathrm{~S}$ adsorption. For $\mathrm{Cu}_{9}-\mathrm{H}_{2} \mathrm{~S}$ interactions we find correlations of $R^{2}=0.941$ for $V_{\mathrm{S} \text {, max }}$ and $R^{2}=0.963$ for $E_{\mathrm{S}, \min }$, comparable to, but slightly weaker than, those of $\mathrm{Ag}_{9}$.

In order to find an explanation to the differences between the particles, we turn to an electronic structure analysis. The three particles are approximately isoelectronic in the valence shell and display similar orbital configuration profiles, with $\mathrm{Au}$ having unoccupied orbitals of slightly lower energy as well as two more unoccupied orbitals below the zero-energy limit compared to the other particles. Apart from that, all orbitals are isolobal for the $\mathrm{Au}, \mathrm{Ag}$ and $\mathrm{Cu}$ particles, with only slight dissimilarities, as can be seen in for instance the LUMO orbitals of
Fig. S4 in the ESI. $\dagger$ Hence the variations in the $V_{\mathrm{S}}(\mathbf{r})$ and $E_{\mathrm{S}}(\mathbf{r})$ amid the particles are due to small differences in their electronic structures, which illustrate the need for a more sophisticated interaction affinity descriptor than e.g. the HOMO and/or LUMO energies. The small deviations between the particles in the correlations of the descriptor values versus adsorption energies can further be explained by geometrical effects upon adsorption, with larger distortions generally giving rise to reduced correlations (see the ESI $\dagger$ ).

As mentioned in the introduction, interactions are often rationalized in terms of contributions of different physical characters. While $V(\mathbf{r})$ obviously provides information on the particles' ability to participate in electrostatic interactions, $E(\mathbf{r})$ also accounts for the ability of the particle to accept electrons in electron-transfer processes taking place upon interactions. The relative influence of electrostatics versus charge-transfer/ polarization in the various interactions is attainable by the formation of a multi-variant combination of the $V_{\mathrm{S} \text {, max }}$ (electrostatics) and $E_{\mathrm{S}, \mathrm{min}}$ (both electrostatics and charge-transfer/ polarization) properties of the different sites of the $\mathrm{Au}_{9}, \mathrm{Ag}_{9}$ and $\mathrm{Cu}_{9}$ particles. First of all, one should note that, although the NPs display differences in both the descriptor properties and in the interaction energies, the $\mathrm{H}_{2} \mathrm{O}$ interaction energies of all the particles put on the same trend line yields a clear correlation with the local values of the individual descriptor, as can be seen in Fig. 8. By this approach, the obtained $R^{2}$ values for $V_{\mathrm{S}, \max }$ and $E_{\mathrm{S} \text {,min }}$ are 0.790 and 0.823 respectively. This can be compared to the corresponding trends for $\mathrm{H}_{2} \mathrm{~S}$ adsorption, which display much weaker correlations with $R^{2}$ values of $0.109\left(V_{\mathrm{S}, \max }\right)$ and $0.502\left(E_{\mathrm{S}, \min }\right)$ respectively (see Fig. 8). By the formation of a linear combination between the $V_{\mathrm{S} \text {, max }}$ and $E_{\mathrm{S} \text {,min }}$ determined at all the unique adsorption sites of the three NPs, the corresponding $\mathrm{H}_{2} \mathrm{O}$ interaction energies are predicted with a $R^{2}$ coefficient of 0.851 , i.e. only moderately better than the individual descriptors. For the case of $\mathrm{H}_{2} \mathrm{~S}$ a more pronounced effect is obtained and the correlation is increased to $R^{2}=0.866$ (Fig. 8). From the above one could argue that in order to capture the variations of the $\mathrm{H}_{2} \mathrm{~S}$ interaction over the different particles, one has to account for both their electrostatic and charge-transfer/polarization capabilities. In contrast, the interaction of $\mathrm{H}_{2} \mathrm{O}$ seems to be of a simpler nature; based on the hard character of $\mathrm{H}_{2} \mathrm{O}$, and the generally good performance of $V_{\mathrm{S} \text {, max }}$ for the estimation of $\mathrm{H}_{2} \mathrm{O}$ interaction energies, it is reasonable to assume that the interactions are dominated by electrostatics for all the considered NPs. The difference between $\mathrm{H}_{2} \mathrm{O}$ and $\mathrm{H}_{2} \mathrm{~S}$ can be further demonstrated by assessing the weighting coefficients in their respective multi-linear combinations: for $\mathrm{H}_{2} \mathrm{O}$ the weighting coefficients of $V_{\mathrm{S}, \max }$ and $E_{\mathrm{S} \text {,min }}$ are -0.134 and 0.495 , whereas for $\mathrm{H}_{2} \mathrm{~S}$ the coefficients are 0.838 and $3.301\left(V_{\mathrm{S}, \max }\right.$ in $\mathrm{kcal} \mathrm{mol}^{-1}$ and $E_{\mathrm{S} \text {,min }}$ in $\mathrm{eV}$ ). Note here that the sign of the $V_{\mathrm{S} \text {,max }}$ coefficient is changed going from $\mathrm{H}_{2} \mathrm{O}$ to $\mathrm{H}_{2} \mathrm{~S}$. Since $E_{\mathrm{S}}(\mathbf{r})$ consists of both electrostatic and charge-transfer/polarization contributions, this indicate that, in order to be able to compare the $\mathrm{H}_{2} \mathrm{~S}$ interaction of the different particles, we have to remove a portion of the electrostatic component. This is in contrast 

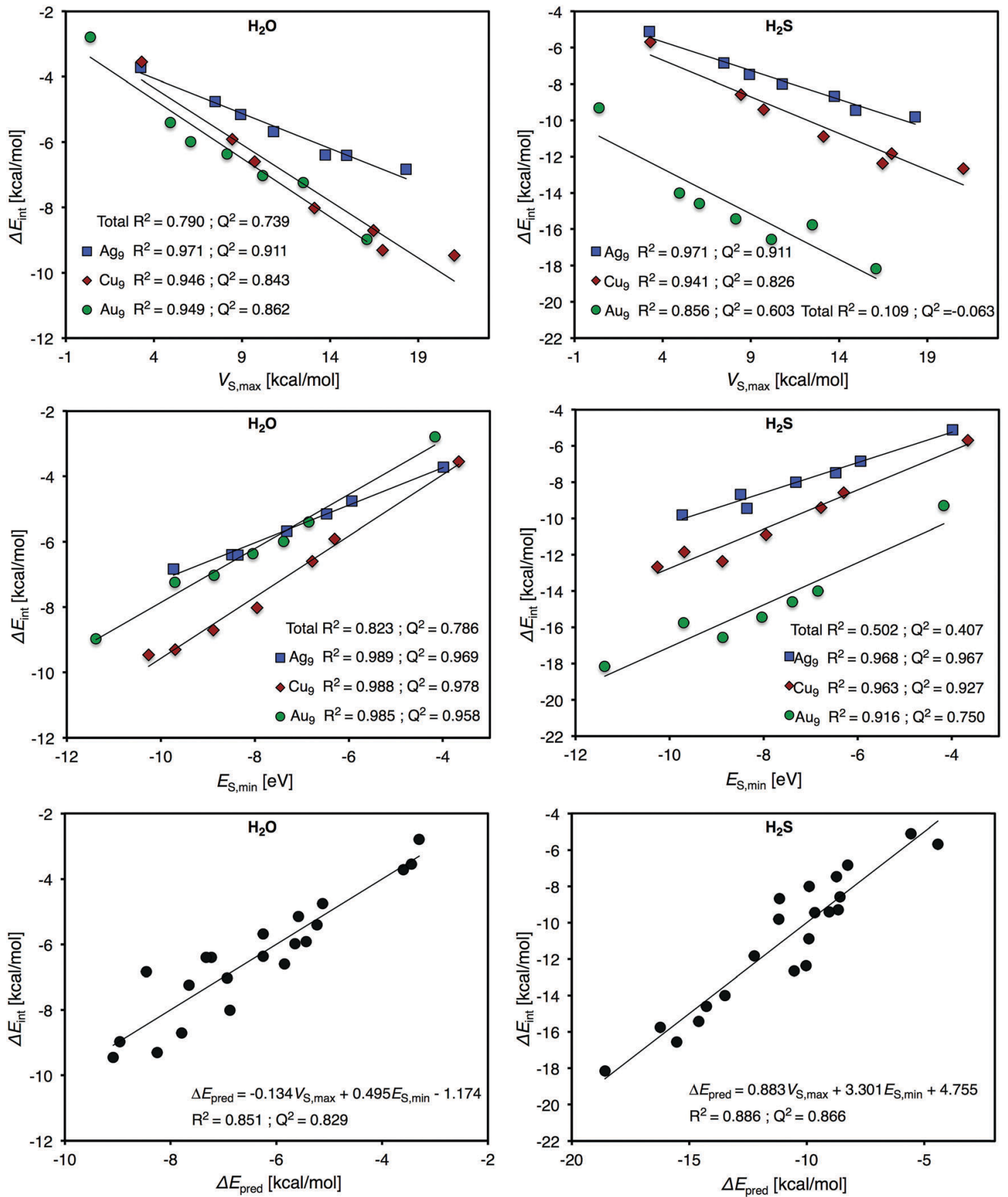

Fig. 8 Correlation plots for $\mathrm{H}_{2} \mathrm{O}$ (left) and $\mathrm{H}_{2} \mathrm{~S}$ (right) interaction energies onto the various sites of the geometrical isomers $\mathrm{Au}_{9}$, $\mathrm{Ag}_{9}$ and $\mathrm{Cu}_{9}$ versus the site resolved $V_{\mathrm{S}, \max }$ (top panel) and $E_{\mathrm{S}, \min }$ (middle panel) obtained at the $0.001 \mathrm{a}$.u. isosurface. The bottommost figures show the calculated interaction energy, $\Delta E_{\text {int, }}$ of $\mathrm{H}_{2} \mathrm{O}$ and $\mathrm{H}_{2} \mathrm{~S}$ versus predicted interaction energies, $\Delta E_{\text {pred }}$, from multi-linear combinations of the $V_{\mathrm{S}, \max }$ and $E_{\mathrm{S} \text {, min. }}$

with $\mathrm{H}_{2} \mathrm{O}$, where the electrostatic component of $E(\mathbf{r})$ instead has to be reinforced.

\subsection{CO adsorption onto $\mathbf{A g}_{9}-\mathbf{A g}_{18}$ particles}

In the study of Duanmu et al., ${ }^{37} \mathrm{CO}$ adsorption energies onto each unique $\mathrm{Ag}$ site were determined for the $\mathrm{Ag}_{9}, \mathrm{Ag}_{11}, \mathrm{Ag}_{17}$ and $\mathrm{Ag}_{18}$ nanoparticles using the $\mathrm{N} 12^{78}$ DFT exchange-correlation functional in combination with the $6-311+\mathrm{G}(2 \mathrm{df}, 2 \mathrm{p})$ basis set for carbon and oxygen and cc-pVDZ-PP for Ag. As described in
Section 3.3, CO interacts C-down and adsorbs at on top sites of the Ag-atoms. The interaction energies range from -3.5 to $-16.1 \mathrm{kcal} \mathrm{mol}^{-1}$. By re-optimization of the adsorption structures on the $\mathrm{Ag}_{9}$ particle, we find binding distances of $2.14 \pm 0.03 \AA$.

Duanmu et $a l .{ }^{37}$ used partial charges to rationalize the variations of the CO interaction energies at different sites of the Ag nanoparticles. As shown in Table 3 , the $V_{\mathrm{S} \text {, max }}$ descriptor performs better than the CM5M partial atomic charges presented in the work of Duanmu et al., both overall and for each of the 
Table 3 Squared coefficients of correlation $\left(R^{2}\right)$ for the site resolved $\mathrm{CO}$ adsorption energies ${ }^{a}$ onto $\mathrm{Ag}_{n}, n=9,11,17$ and 18, compared to local descriptor values of $V_{S}(\mathbf{r}), E_{S}(\mathbf{r})$ and $\bar{l}_{S}(\mathbf{r})$ on both the 0.004 a.u. and 0.001 a.u. isosurfaces as well as CM5M, Mulliken, Bader and NBO partial charges. Cross-correlated $R^{2}=Q^{2}$, and standard errors (SE) for the total series are included for comparison

\begin{tabular}{|c|c|c|c|c|c|c|c|c|c|c|c|}
\hline & $V_{0.004}$ & $V_{0.001}$ & $E_{0.004}^{b}$ & $E_{0.001}{ }^{c}$ & $V+E^{d}$ & $\bar{I}_{\mathrm{S}, \text { ave }}$ & $E+I^{e}$ & $\mathrm{CM} \mathrm{M}^{a}$ & Mulliken & Bader & NBO \\
\hline $\mathrm{Ag}_{11}$ & $0.907^{f}$ & $0.868^{f}$ & $0.743^{f}$ & $0.761^{f}$ & 0.832 & 0.516 & 0.794 & 0.79 & 0.135 & 0.074 & 0.614 \\
\hline $\mathrm{Ag}_{17}$ & 0.828 & 0.838 & 0.942 & 0.941 & 0.901 & 0.938 & 0.960 & 0.84 & 0.072 & 0.001 & 0.440 \\
\hline Total & 0.817 & 0.819 & 0.835 & 0.819 & 0.839 & 0.731 & $0.850^{g}$ & 0.73 & 0.047 & 0.030 & 0.427 \\
\hline$Q^{2}$ & 0.779 & 0.786 & 0.804 & 0.782 & 0.808 & 0.690 & 0.822 & 0.68 & -0.111 & -0.072 & 0.357 \\
\hline
\end{tabular}

${ }^{a}$ From ref. 37. ${ }^{b} \mathrm{The} \mathrm{Ag}_{9}(2), \mathrm{Ag}_{17}(1), \mathrm{Ag}_{17}(5), \mathrm{Ag}_{18}(1), \mathrm{Ag}_{18}(6), \mathrm{Ag}_{18}(7)$ and $\mathrm{Ag}_{18}(8)$ sites of the 0.004 a.u. isodensity surface have no true minimum in $E(\mathbf{r}){ }^{c}$ The $\mathrm{Ag}_{9}(2), \mathrm{Ag}_{11}(4), \mathrm{Ag}_{17}(1), \mathrm{Ag}_{17}(5), \mathrm{Ag}_{18}(1), \mathrm{Ag}_{18}(3), \mathrm{Ag}_{18}(6), \mathrm{Ag}_{18}(7)$ and $\mathrm{Ag}_{18}(8)$ sites of the 0.001 a.u. isodensity surface have no true minimum in $E(\mathbf{r})$. Instead the $E(\mathbf{r})$ values on the isodensity surface along the Ag-nucleophile bond were used. ${ }^{d}$ Estimated interaction energy obtained by a linear combination of $V=V_{0.001}(\mathbf{r})$ and $E=E_{0.001}(\mathbf{r}): \Delta E_{\text {int }}($ estimated $)=0.256 V-0.034 E-0.048\left[\mathrm{kcal}^{-1} \mathrm{~mol}^{-1}\right] .{ }^{e}$ Estimated interaction energy obtained by a linear combination of $E=E_{0.001}(\mathbf{r})$ and $I=\bar{I}_{\mathrm{S} \text {,ave }}: \Delta E_{\text {int }}($ estimated $)=-0.047 E+0.257 I-37.420\left[\mathrm{kcal}^{\mathrm{mol}}{ }^{-1}\right] .{ }^{f} \mathrm{The}^{\mathrm{T}}$ corresponding $R^{2}$ with $\mathrm{H}_{2} \mathrm{O}$ adsorption energies at the PBE0-D3(BJ)/def2-TVZPP $/ / \mathrm{PBE} 0-\mathrm{D} 3(\mathrm{BJ}) / \mathrm{def} 2-\mathrm{TVZP}$ level of theory is $V_{0.004}=0.950$ and $V_{0.001}=$ 0.938 as well as $E_{0.004}=0.919$ and $E_{0.001}=0.922 .{ }^{g}$ A similar linear combination of $V+I$ gives a $R^{2}$ of 0.830 .

particles separately. The same is true when comparing $V_{\mathrm{S}, \max }$ to atomic charges obtained by other protocols, including Mulliken, Bader and NBO charges. The success of $V_{\mathrm{S} \text {, max }}$ is not surprising in this context. In contrast to partial charges, the electrostatic potential is a rigorously defined property and provides an unbiased understanding of the interaction. In addition, the local electrostatic potential is a physical observable and its spatial variations are known to be influential in directing chemical interactions. ${ }^{8}$

Regarding the $E_{\mathrm{S}}(\mathbf{r})$ descriptor, it gives the best overall correlation amongst all individual descriptors if evaluated at the 0.004 a.u. isosurface, but performs poorly for the $\mathrm{Ag}_{11}$ particle. This can be traced to an underestimation of the interaction strength at the $\operatorname{Ag}_{11}(7)$ site, which is also manifested, but to a smaller degree, for the $V_{\mathrm{S}}(\mathbf{r})$ descriptor. On the other hand, the $E_{\mathrm{S}}(\mathbf{r})$ correlation for the $\mathrm{CO}$ adsorption onto the $\mathrm{Ag}_{17}$ particle is very good with a coefficient of determination $\left(R^{2}\right)$ of 0.942 on the 0.004 a.u. isodensity surface. Moving on over the series of $\mathrm{Ag}$ particles, we find that $E_{\mathrm{S}}(\mathbf{r})$ indeed performs well as an indicator of the CO-affinity. The performances of both $E_{\mathrm{S}}(\mathbf{r})$ and $V_{\mathrm{S}}(\mathbf{r})$ for CO adsorption are, however, slightly inferior to that of e.g. $\mathrm{H}_{2} \mathrm{O}$ adsorption, and could be linked to the mixed donor-acceptor interaction character of $\mathrm{CO}$, as pointed out previously in Section 3.2, whereas $\mathrm{H}_{2} \mathrm{O}$ is purely an electron donor. Fig. 9 gives an overview of the performances of $V_{\mathrm{S}}(\mathbf{r})$ and $E_{\mathrm{S}}(\mathbf{r})$ for the estimations of the local CO-affinity evaluated on the 0.001 a.u. isodensity surfaces.

In addition to the analysis on the 0.004 a.u. isodensity surface, $V_{\mathrm{S} \text {, max }}$ and $E_{\mathrm{S} \text {, min }}$ values obtained on the 0.001 a.u. isosurface are also included in Table 3. Although the differences are small, the comparison suggest that the 0.004 a.u. isosurface is slightly better overall for $E_{\mathrm{S}}(\mathbf{r})$ while for $V_{\mathrm{S}}(\mathbf{r})$ the 0.001 and 0.004 a.u. isosurfaces give similar predictions of the $\mathrm{Ag}$ NP CO affinity. However, for the interactions with other adsorbates and including the $\mathrm{Au}$ and $\mathrm{Cu}$ particles, the general conclusion is that the 0.001 a.u. isosurface gives slightly more accurate results than the 0.004 a.u. isosurface for the group 11 metal NPs.
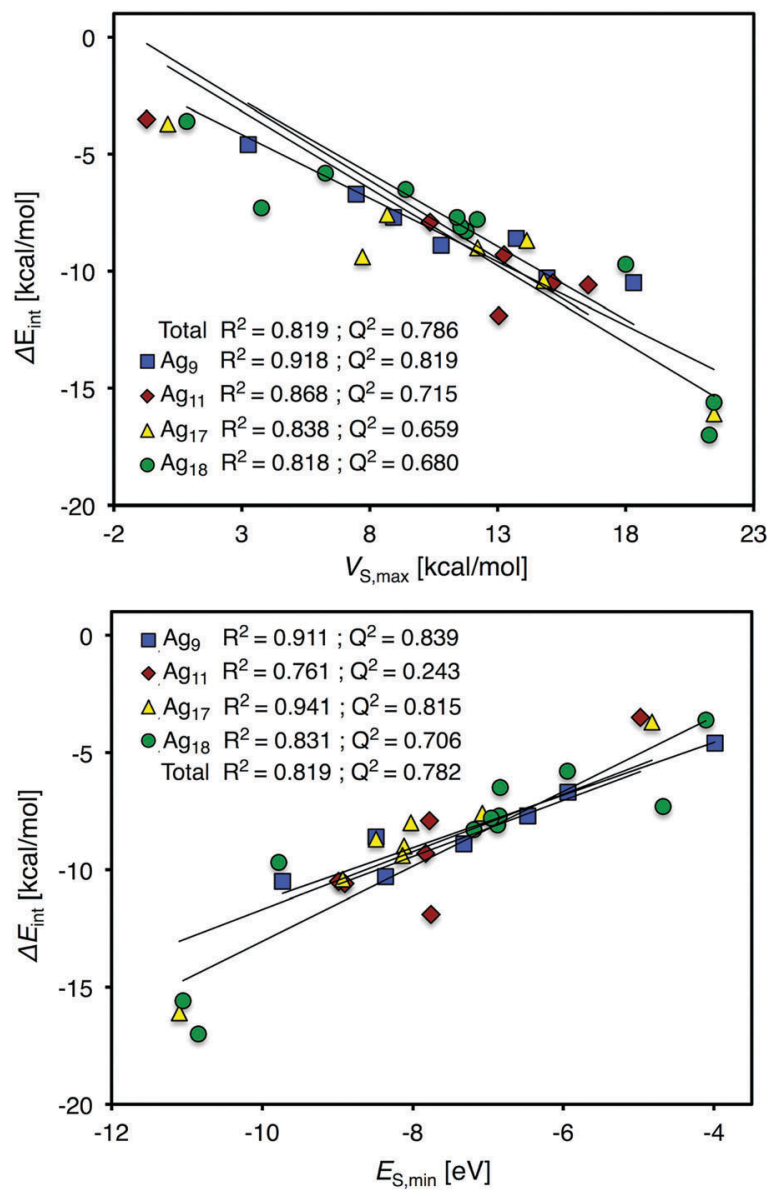

Fig. 9 Plots presenting the correlation between site-resolved $\mathrm{CO}$ adsorption energies and descriptor values at the adsorption sites for the $\mathrm{Ag}_{9}, \mathrm{Ag}_{11}$, $\mathrm{Ag}_{17}$ and $\mathrm{Ag}_{18}$ nanoparticles separately and combined (total). $V_{\mathrm{S}, \max }$ (top) and $E_{\mathrm{S} \text {, min }}$ (bottom) were obtained at the 0.001 a.u. isodensity surface.

Since $E(\mathbf{r})$ and $V(\mathbf{r})$ are known to provide complementary information to some degree, ${ }^{23}$ it is not surprising that a multilinear combination of $E(\mathbf{r})$ and $V(\mathbf{r})$, as seen in Table 3, increases the correlation with the interaction energies - this 
is because we are now able to describe a larger portion of the interaction energy. We, furthermore, find that the dual Lewis acid/base character of $\mathrm{CO}$ is reflected by the finding that the $\bar{I}_{\mathrm{S}}(\mathbf{r})$ Lewis basicity descriptor correlates fairly well with the CO adsorption energies $\left[\bar{I}_{\mathrm{S}}(\mathbf{r})\right.$ is here in the form of the mean average local surface ionization potential at the 0.001 a.u. isosurface, $\bar{I}_{\mathrm{S} \text {,ave, }}$ of the atom of interaction since minima in $\bar{I}_{\mathrm{S}}(\mathbf{r})$ could in general not be identified at the atomic sites]. The mixed electron donor/acceptor character of $\mathrm{CO}$ is further supported by the fact that a multi-linear combination of $\bar{I}_{\mathrm{S} \text {,ave }}$ and $E_{\mathrm{S} \text {,min }}$ gives the best overall correlation with the CO-Ag-particle interactions $\left(R^{2}=0.850\right)$.

\section{Conclusion}

In the current work we have evaluated the performance of a series of isodensity surface based DFT-descriptors for analyzing and predicting local Lewis acidity and basicity. The evaluation was carried out on a selection of $\mathrm{Ag}, \mathrm{Au}$ and $\mathrm{Cu}$ nanoparticles, by correlating descriptor values with site-resolved interaction energies of small probe molecules. The descriptors include the density dependent surface electrostatic potential $\left[V_{\mathrm{S}}(\mathbf{r})\right]$ as well as two multi-orbital descriptors: the surface average local ionization potential $\left[\bar{I}_{\mathrm{S}}(\mathbf{r})\right]$ that characterizes the local electron donating capacity of the particles, and the local surface electron attachment energy $\left[E_{\mathrm{S}}(\mathbf{r})\right]$ that depicts the local electron acceptor capacity of the particle. Qualitatively, both electron donating and accepting properties are well described. From adsorption studies of small probe molecules, we conclude that positions of high susceptibility towards electron-accepting compounds are found at bridge and hollow sites of the noble metal nanoparticles. Upon interactions with electron-donors, the atomic on top sites are instead favored. These findings coincide with areas of high Lewis acidity and basicity defined by the descriptors, e.g., Lewis acidic areas of high $V_{\mathrm{S}}(\mathbf{r})$, i.e. $\sigma$-holes, correspond to adsorption sites for electron donors, whereas Lewis basic sites of low $V_{\mathrm{S}}(\mathbf{r})$, i.e. $\sigma$-lumps, adsorb electron acceptors.

We find that the interaction energies for the adsorption of $\mathrm{CO}, \mathrm{H}_{2} \mathrm{O}, \mathrm{NH}_{3}$ and $\mathrm{H}_{2} \mathrm{~S}$ Lewis bases can be successfully ranked, both by local maxima in $V_{\mathrm{S}}(\mathbf{r})$, $\sigma$-holes, as well as minima in $E_{\mathrm{S}}(\mathbf{r})$ at the on top sites of the noble metal nanoparticles. The descriptors readily outperform the comparatively simple FMO concept and have a much larger predictive power than partial atomic charges obtained by various protocols. Due to the similarity between halogen and hydrogen bonding and the interaction of the NPs with electron donors $\left(\right.$ e.g. $\left.\mathrm{H}_{2} \mathrm{O}\right)$ via sites of high $V_{\mathrm{S}}(\mathbf{r})$, i.e. $\sigma$-holes, we have introduced a new class of bonds - regium bonds - where the name reflects the noble character of the $\mathrm{Cu}, \mathrm{Ag}$, and $\mathrm{Au}$ metals.

As concerning the interactions with the $\mathrm{BH}_{3}, \mathrm{BF}_{3}, \mathrm{HCl}$, and $\mathrm{Na}^{+}$electron accepting probe compounds, the same quality of correlation cannot be obtained as for the interactions with electron donors. This is attributed to an increased level of complexity upon interactions, including adsorbate bending, multi-atom interaction and rearrangement of the substrate nanoparticle.

We have further described that the $\bar{I}_{\mathrm{S}}(\mathbf{r})$ and $E_{\mathrm{S}}(\mathbf{r})$ descriptors provide complementary information to $V_{\mathrm{S}}(\mathbf{r})$ with regard to the different contributions to the interaction energy: $V_{\mathrm{S}}(\mathbf{r})$ reflects the electrostatic part of the interactions while $\bar{I}_{\mathrm{S}}(\mathbf{r})$ and $E_{\mathrm{S}}(\mathbf{r})$ also quantify the metal particles' charge transfer/polarization abilities. Although $E_{\mathrm{S}}(\mathbf{r})$ and $\bar{I}_{\mathrm{S}}(\mathbf{r})$ display excellent capabilities to identify and rank nanoparticle adsorption sites, we find from our analysis that the adsorption sites are best identified by $V_{\mathrm{S} \text {, max }}$ and $V_{\mathrm{S} \text {,min }}$. Accordingly, electrostatics is expected to be the dominating factor for interactions with hard species. Nevertheless, we also find that in order to reflect trends in the interaction energies of the $\mathrm{Cu}, \mathrm{Ag}$ and $\mathrm{Au}$ particles with e.g. the soft $\mathrm{H}_{2} \mathrm{~S}$ molecule, both electrostatic and charge-transfer/polarization effects have to be included.

As has previously been demonstrated within the field of molecular chemistry, we anticipate that the tested descriptors will be broadly applicable in the nanoparticle and materials sciences. In the near future we will show this for systems ranging from nanoparticles of various sizes and composition to semiinfinite materials and surfaces including metals and metal oxides. The findings of the present study are envisaged to have implications in areas as diverse as heterogeneous catalysis, nucleation/dissolution processes, particle transportation, chromatography, corrosion and nanotoxicology.

\section{Conflicts of interest}

There are no conflicts to declare.

\section{Acknowledgements}

The authors gratefully acknowledge the financial support from the Swedish Nuclear Fuel and Waste Management Company (SKB) and the School of Chemical Science and Engineering at KTH (via its Excellence award to J. H. S.). The calculations were performed at resources provided by the Swedish National Infrastructure for Computing (SNIC) at the National Supercomputer Centre (NSC) in Linköping University as well as at the PDC Center for High Performance Computing (PDC-HPC).

\section{References}

1 R. Ferrando, J. Jellinek and R. L. Johnston, Nanoalloys: From Theory to Applications of Alloy Clusters and Nanoparticles, Chem. Rev., 2008, 108, 845-910.

2 J. Kim, J. E. Dick and A. J. Bard, Advanced Electrochemistry of Individual Metal Clusters Electrodeposited Atom by Atom to Nanometer by Nanometer, Acc. Chem. Res., 2016, 49, 2587-2595.

3 Z. Luo, A. W. Castleman and S. N. Khanna, Reactivity of Metal Clusters, Chem. Rev., 2016, 116, 14456-14492.

4 M. Haruta and M. Daté, Advances in the catalysis of $\mathrm{Au}$ nanoparticles, Appl. Catal., A, 2001, 222, 427-437. 
5 N. Zhou, V. López-Puente, Q. Wang, L. Polavarapu, I. Pastoriza-Santos and Q.-H. Xu, Plasmon-enhanced light harvesting: applications in enhanced photocatalysis, photodynamic therapy and photovoltaics, $R S C A d v$., 2015, 5, 29076-29097.

6 P. Di Pietro, G. Strano, L. Zuccarello and C. Satriano, Gold and Silver Nanoparticles for Applications in Theranostics, Curr. Top. Med. Chem., 2016, 16, 3069-3102.

7 E. Roduner, Size matters: why nanomaterials are different, Chem. Soc. Rev., 2006, 35, 583-592.

8 J. S. Murray and P. Politzer, The electrostatic potential: an overview, Wiley Interdiscip. Rev.: Comput. Mol. Sci., 2011, 1, 153-163.

9 J. H. Stenlid, A. J. Johansson and T. Brinck, Searching for the thermodynamic limit - a DFT study of the step-wise water oxidation of the bipyramidal $\mathrm{Cu}_{7}$ cluster, Phys. Chem. Chem. Phys., 2014, 16, 2452-2464.

10 D. Farmanzadeh and T. Abdollahi, Investigation on the chemical active sites of copper nanoclusters as nanocatalyst for the adsorption of acetylene: calibration of DFT method and basis set, Theor. Chem. Acc., 2016, 135, 1-14.

11 D. Farmanzadeh and T. Abdollahi, a model for the ethylene and acetylene adsorption on the surface of $\mathrm{Cu}_{n}(n=10-15)$ nanoclusters: A theoretical study, Appl. Surf. Sci., 2016, 385, 241-248.

12 J. H. Stenlid, A. J. Johansson and T. Brinck, $\sigma$-Holes on Transition Metal Nanoclusters and Their Influence on the Local Lewis Acidity, Crystals, 2017, 7, 222.

13 J. H. Stenlid and T. Brinck, Extending the $\sigma$-Hole Concept to Metals: An Electrostatic Interpretation of the Effects of Nanostructure in Gold and Platinum Catalysis, J. Am. Chem. Soc., 2017, 139, 11012-11015.

14 P. Politzer and J. S. Murray, The fundamental nature and role of the electrostatic potential in atoms and molecules, Theor. Chem. Acc., 2002, 108, 134-142.

15 T. Brinck, J. S. Murray and P. Politzer, Surface electrostatic potentials of halogenated methanes as indicators of directional intermolecular interactions, Int. J. Quantum Chem., 1992, 44, 57-64.

16 P. Politzer, P. Lane, M. C. Concha, Y. Ma and J. S. Murray, An overview of halogen bonding, J. Mol. Model., 2007, 13, 305-311.

17 T. Clark, M. Hennemann, J. Murray and P. Politzer, Halogen bonding: the $\sigma$-hole, J. Mol. Model., 2007, 13, 291-296.

18 T. Brinck, in Theoretical Organic Chemistry, ed. C. Párkányi, Elsevier Science B.V., Amsterdam, 1st edn, 1998, vol. 5.

19 E. D. Stevens, Experimental electron density distribution of molecular chlorine, Mol. Phys., 1979, 37, 27-45.

20 S. J. Harris, S. E. Novick, J. S. Winn and W. Klemperer, $\left(\mathrm{Cl}_{2}\right)_{2}$ : A polar molecule, J. Chem. Phys., 1974, 61, 3866-3867.

21 R. G. Pearson, Chemical Hardness, Wiley-VCH Verlag GmbH \& Co. KGaA, 1997, pp. 1-27.

22 P. Sjoberg, J. S. Murray, T. Brinck and P. Politzer, Average local ionization energies on the molecular surfaces of aromatic systems as guides to chemical reactivity, Can. J. Chem., 1990, 68, 1440-1443.
23 T. Brinck, P. Carlqvist and J. H. Stenlid, Local Electron Attraction Energy and its Use for Predicting Nucleophilic Reactions and Halogen Bonding, J. Phys. Chem. A, 2016, 120, 10023-10032.

24 T. Brinck, J. S. Murray and P. Politzer, Relationships between the aqueous acidities of some carbon, oxygen, and nitrogen acids and the calculated surface local ionization energies of their conjugate bases, J. Org. Chem., 1990, 56, 5012-5015.

25 P. Politzer, J. S. Murray and F. A. Bulat, Average local ionization energy: A review, J. Mol. Model., 2010, 16, 1731-1742.

26 J. H. Stenlid and T. Brinck, Nucleophilic Aromatic Substitution Reactions Described by the Local Electron Attachment Energy, J. Org. Chem., 2017, 82, 3072-3083.

27 F. A. Bulat, M. Levy and P. Politzer, Average Local Ionization Energies in the Hartree-Fock and Kohn-Sham Theories, J. Phys. Chem. A, 2009, 113, 1384-1389.

28 T. Brinck, J. S. Murray and P. Politzer, Molecular surface electrostatic potentials and local ionization energies of Group V-VII hydrides and their anions: Relationships for aqueous and gas-phase acidities, Int. J. Quantum Chem., 1993, 48, 73-88.

29 B. Ehresmann, B. Martin, A. H. C. Horn and T. Clark, Local molecular properties and their use in predicting reactivity, J. Mol. Model., 2003, 9, 342-347.

30 T. Clark, The local electron affinity for non-minimal basis sets, J. Mol. Model., 2010, 16, 1231-1238.

31 J. F. Janak, Proof that $\partial E / \partial n_{\mathrm{i}}=\varepsilon_{\mathrm{i}}$ in density-functional theory, Phys. Rev. B: Solid State, 1978, 18, 7165-7168.

32 M. J. Frisch, G. W. Trucks, H. B. Schlegel, G. E. Scuseria, M. A. Robb, J. R. Cheeseman, G. Scalmani, V. Barone, B. Mennucci and G. A. Petersson, et al., Gaussian 09, Revision D.01, Gaussian, Inc., Wallingford, CT, 2009.

33 C. Adamo and V. Barone, Toward reliable density functional methods without adjustable parameters: the PBE0 model, J. Chem. Phys., 1999, 110, 6158-6170.

34 S. Grimme, J. Antony, S. Ehrlich and H. Krieg, A consistent and accurate $\mathrm{ab}$ initio parametrization of density functional dispersion correction (DFT-D) for the 94 elements $\mathrm{H}-\mathrm{Pu}$, J. Chem. Phys., 2010, 132, 154104.

35 S. Grimme, S. Ehrlich and L. Goerigk, Effect of the damping function in dispersion corrected density functional theory, J. Comput. Chem., 2011, 32, 1456-1465.

36 F. Weigend and R. Ahlrichs, Balanced basis sets of split valence, triple zeta valence and quadruple zeta valence quality for $\mathrm{H}$ to $\mathrm{Rn}$ : design and assessment of accuracy, Phys. Chem. Chem. Phys., 2005, 7, 3297.

37 K. Duanmu and D. G. Truhlar, Partial Ionic Character beyond the Pauling Paradigm: Metal Nanoparticles, J. Phys. Chem. C, 2014, 118, 28069-28074.

38 Y. Zhao and D. G. Truhlar, A new local density functional for main-group thermochemistry, transition metal bonding, thermochemical kinetics, and noncovalent interactions, J. Chem. Phys., 2006, 125, 194101.

39 M. M. Quintal, A. Karton, M. A. Iron, A. D. Boese and J. M. L. Martin, Benchmark Study of DFT Functionals for 
Late-Transition-Metal Reactions, J. Phys. Chem. A, 2006, 110, 709-716.

40 S. C. Ammal and A. Heyden, Modeling the noble metal/ $\mathrm{TiO}_{2}(110)$ interface with hybrid DFT functionals: a periodic electrostatic embedded cluster model study, J. Chem. Phys., 2010, 133, 164703.

41 C. Di Valentin, G. Pacchioni and A. Selloni, Electronic Structure of Defect States in Hydroxylated and Reduced Rutile $\mathrm{TiO}_{2}$ (110) Surfaces, Phys. Rev. Lett., 2006, 97, 166803.

42 C. M. Lousada, A. J. Johansson, T. Brinck and M. Jonsson, Reactivity of metal oxide clusters with hydrogen peroxide and water - a DFT study evaluating the performance of different exchange-correlation functionals, Phys. Chem. Chem. Phys., 2013, 15, 5539-5552.

43 M. Bühl, C. Reimann, D. A. Pantazis, T. Bredow and F. Neese, Geometries of Third-Row Transition-Metal Complexes from Density-Functional Theory, J. Chem. Theory Comput., 2008, 4, 1449-1459.

$44 \mathrm{~J}$. Carrasco, J. Klimeš and A. Michaelides, The role of van der Waals forces in water adsorption on metals, J. Chem. Phys., 2013, 138, 24708.

45 J. Carrasco, B. Santra, J. Klimeš and A. Michaelides, To Wet or Not to Wet? Dispersion Forces Tip the Balance for Water Ice on Metals, Phys. Rev. Lett., 2011, 106, 26101.

46 J. P. Perdew, K. Burke and M. Ernzerhof, Generalized Gradient Approximation Made Simple, Phys. Rev. Lett., 1996, 77, 3865-3868.

47 J. Heyd, G. E. Scuseria and M. Ernzerhof, Hybrid functionals based on a screened Coulomb potential, J. Chem. Phys., 2003, 118, 8207-8215.

48 J. Heyd, G. E. Scuseria and M. Ernzerhof, Erratum: "Hybrid functionals based on a screened Coulomb potential" [J. Chem. Phys., 118, 8207 (2003)], J. Chem. Phys., 2006, 124, 219906.

49 O. A. Vydrov and G. E. Scuseria, Assessment of a long-range corrected hybrid functional, J. Chem. Phys., 2006, 125, 234109.

50 V. N. Staroverov, G. E. Scuseria, J. Tao and J. P. Perdew, Comparative assessment of a new nonempirical density functional: Molecules and hydrogen-bonded complexes, J. Chem. Phys., 2003, 119, 12129-12137.

51 V. N. Staroverov, G. E. Scuseria, J. Tao and J. P. Perdew, Erratum: "Comparative assessment of a new nonempirical density functional: Molecules and hydrogen-bonded complexes" [J. Chem. Phys., 119, 12129 (2003)], J. Chem. Phys., 2004, 121, 11507.

52 A. D. Becke, Density-functional thermochemistry. III. The role of exact exchange, J. Chem. Phys., 1993, 98, 5648-5652.

53 P. J. Stephens, F. J. Devlin, C. F. Chabalowski and M. J. Frisch, Ab Initio Calculation of Vibrational Absorption and Circular Dichroism Spectra Using Density Functional Force Fields, J. Phys. Chem., 1994, 98, 11623-11627.

54 T. Yanai, D. P. Tew and N. C. Handy, A new hybrid exchange-correlation functional using the Coulombattenuating method (CAM-B3LYP), Chem. Phys. Lett., 2004, 393, 51-57.
55 M. Reiher, O. Salomon and B. A. Hess, Reparameterization of hybrid functionals based on energy differences of states of different multiplicity, Theor. Chem. Acc., 2001, 107, 48-55.

56 A. Slimani, X. Yu, A. Muraoka, K. Boukheddaden and K. Yamashita, Reparametrization Approach of DFT Functionals Based on the Equilibrium Temperature of SpinCrossover Compounds, J. Phys. Chem. A, 2014, 118, 9005-9012.

57 P. E. M. Siegbahn, The performance of hybrid DFT for mechanisms involving transition metal complexes in enzymes, J. Biol. Inorg. Chem., 2006, 11, 695-701.

58 P. E. M. Siegbahn and F. Himo, Recent developments of the quantum chemical cluster approach for modeling enzyme reactions, J. Biol. Inorg. Chem., 2009, 14, 643-651.

59 P. J. Hay and W. R. Wadt, Ab initio effective core potentials for molecular calculations. Potentials for the transition metal atoms Sc to Hg, J. Chem. Phys., 1985, 82, 270-283.

60 W. R. Wadt and P. J. Hay, Ab initio effective core potentials for molecular calculations. Potentials for main group elements Na to Bi, J. Chem. Phys., 1985, 82, 284-298.

61 P. J. Hay and W. R. Wadt, Ab initio effective core potentials for molecular calculations. Potentials for $\mathrm{K}$ to $\mathrm{Au}$ including the outermost core orbitals, J. Chem. Phys., 1985, 82, 299-310.

62 Jaguar, version 7.9, User Manual, Schrödinger LLC: New York, 2014.

63 E. D. Glendening, A. E. Reed, J. E. Carpenter and F. Weinhold, The NBO Version 3.1, 1990.

64 R. S. Mulliken, Electronic Population Analysis on LCAO-MO Molecular Wave Functions. I, J. Chem. Phys., 1955, 23, 1833-1840.

65 R. F. W. W. Bader, Atoms in Molecules - A Quantum Theory, Oxford University Press, 1990.

66 A. V. Marenich, S. V. Jerome, C. J. Cramer and D. G. Truhlar, Charge Model 5: An Extension of Hirshfeld Population Analysis for the Accurate Description of Molecular Interactions in Gaseous and Condensed Phases, J. Chem. Theory Comput., 2012, 8, 527-541.

67 A. R. Leach, Molecular Modeling: Principles and Applications, Pearson Education, Ltd, Harlow, England, 2nd edn, 2001.

68 T. Brinck, Modified Interaction Properties Function for the Analysis and Prediction of Lewis Basicities, J. Phys. Chem. A, 1997, 101, 3408-3415.

69 G. Blyholder, Molecular Orbital View of Chemisorbed Carbon Monoxide, J. Phys. Chem., 1964, 68, 2772-2777.

70 B. Hammer, Y. Morikawa and J. K. Nørskov, CO Chemisorption at Metal Surfaces and Overlayers, Phys. Rev. Lett., 1996, 76, 2141-2144.

71 A. Poater, M. Duran, P. Jaque, A. Toro-Labbé and M. Solà, Molecular Structure and Bonding of Copper Cluster Monocarbonyls $\mathrm{Cu}_{n} \mathrm{CO}(n=1-9)$ J. Phys. Chem. B, 2006, 110, 6526-6536.

72 L. G. M. Pettersson and A. Nilsson, A Molecular Perspective on the d-Band Model: Synergy Between Experiment and Theory, Top. Catal., 2014, 57, 2-13. 
73 A. Föhlisch, M. Nyberg, J. Hasselström, O. Karis, L. G. M. Pettersson and A. Nilsson, How Carbon Monoxide Adsorbs in Different Sites, Phys. Rev. Lett., 2000, 85, 3309-3312.

74 A. Föhlisch, M. Nyberg, P. Bennich, L. Triguero, J. Hasselström, O. Karis, L. G. M. Pettersson and A. Nilsson, The bonding of CO to metal surfaces, J. Chem. Phys., 2000, 112, 1946-1958.

75 M. Mantina, A. C. Chamberlin, R. Valero, C. J. Cramer and D. G. Truhlar, Consistent van der Waals Radii for the Whole Main Group, J. Phys. Chem. A, 2009, 113, 5806-5812.
76 A. Bondi, van der Waals Volumes and Radii, J. Phys. Chem., 1964, 68, 441-451.

77 H. Häkkinen, S. Abbet, A. Sanchez, U. Heiz and U. Landman, Structural, Electronic, and Impurity-Doping Effects in Nanoscale Chemistry: Supported Gold Nanoclusters, Angew. Chem., Int. Ed., 2003, 42, 1297-1300.

78 R. Peverati and D. G. Truhlar, Exchange-Correlation Functional with Good Accuracy for Both Structural and Energetic Properties while Depending Only on the Density and Its Gradient, J. Chem. Theory Comput., 2012, 8, 2310-2319. 